Cite this: Nanoscale, 2014, 6, 6245

\title{
Integrated graphene/nanoparticle hybrids for biological and electronic applications
}

Received 2nd February 2014 Accepted 25th March 2014

DOI: $10.1039 / \mathrm{c} 4 \mathrm{nr} 00612 \mathrm{~g}$

www.rsc.org/nanoscale

\begin{abstract}
Kim Truc Nguyen ${ }^{a}$ and Yanli Zhao*ab
The development of novel graphene/nanoparticle hybrid materials is currently the subject of tremendous research interest. The intrinsic exceptional assets of both graphene (including graphene oxide and reduced graphene oxide) and nanoparticles render their hybrid materials synergic properties that can be useful in various applications. In this feature review, we highlight recent developments in graphene/ nanoparticle hybrids and their promising potential in electronic and biological applications. First, the latest advances in synthetic methods for the preparation of the graphene/nanoparticle hybrids are introduced, with the emphasis on approaches to (1) decorate nanoparticles onto two-dimensional graphene and (2) wrap nanoparticles with graphene sheets. The pros and cons of large-scale synthesis are also discussed. Then, the state-of-the-art of graphene/nanoparticle hybrids in electronic and biological applications is reviewed. For electronic applications, we focus on the advantages of using these hybrids in transparent conducting films, as well as energy harvesting and storage. Biological applications, electrochemical biosensing, bioimaging, and drug delivery using the hybrids are showcased. Finally, the future research prospects and challenges in this rapidly developing area are discussed.
\end{abstract}

${ }^{a}$ Division of Chemistry and Biological Chemistry, School of Physical and Mathematical Sciences, Nanyang Technological University, 21 Nanyang Link, 637371 Singapore. E-mail: zhaoyanli@ntu.edu.sg; Tel: +65 63168792

${ }^{5}$ School of Materials Science and Engineering, Nanyang Technological University, 639798 Singapore

\section{Introduction}

Graphene - a material that appears in almost every research area nowadays - is a shining star on account of its intrinsic outstanding physicochemical properties. The two-dimensional (2D) $\mathrm{sp}^{2}$ carbon network in the graphene structure makes it the

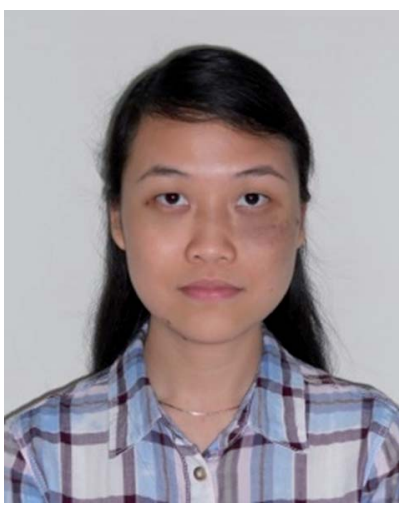

Kim Truc Nguyen received her B.Sc. (Hons) degree in Chemistry from Nanyang Technological University (NTU) Singapore in 2011. She is currently pursuing her Ph.D. studies under the supervision of Professor Yanli Zhao at NTU. Her research focuses on photo-induced charge transfer within nanoparticle/ graphene hybrids and biological applications of silica/graphene hybrids.

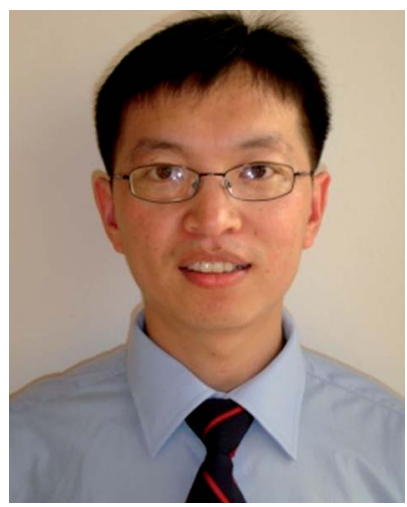

Yanli Zhao is currently a Nanyang Assistant Professor and a National Research Foundation Fellow at Nanyang Technological University, Singapore. He received his B.Sc. degree in Chemistry from Nankai University in 2000 and his Ph.D. degree in Physical Chemistry there in 2005 under the supervision of Professor Yu Liu. He was a postdoctoral scholar with Professor Sir Fraser Stoddart at University of California Los Angeles (October 2005 to November 2008) and subsequently at Northwestern University (January 2010 to August 2010). In between (December 2008 to December 2009), he was a postdoctoral scholar with Professor Jeffrey Zink at University of California Los Angeles. He has published over 100 scientific papers. His current research focuses on biocompatible nanoparticles for diagnostics and therapeutics, and porous materials for energy storage and catalysis. 
thinnest but strongest material in the universe. ${ }^{\mathbf{1 , 2}}$ Due to its unique single atomic layer configuration, graphene possesses an extremely high surface area to mass ratio (theoretically $\left.2630 \mathrm{~m}^{2} \mathrm{~g}^{-1}\right){ }^{3}$ excellent thermal conductivity (3000-5000 W $\mathrm{m}^{-1} \mathrm{~K}^{-1}, 10$ times better than copper), ${ }^{\mathbf{4}, 5}$ optical transparency ( 97.7\%), ${ }^{6-9}$ high electron mobility $\left(10000 \mathrm{~cm}^{2} \mathrm{~V}^{-1} \mathrm{~s}^{-1}\right),{ }^{10-12}$ and other very useful properties. ${ }^{13-18}$ Although the electronic structure of graphene was studied theoretically by P. R. Wallace in $1947,{ }^{19}$ monolayers of graphene were only actually obtained for the first time after a further 57 years. In 2004, A. Geim and K. Novoselov published their results in Science, describing the fabrication, identification and characterization of single layer graphene. ${ }^{20}$ Since then, research on graphene has become a hot topic, recognized by the exponential increase in the number of publications per year (Fig. 1).

However, its inert chemical properties and the difficulty in obtaining defect-free graphene have limited its large-scale synthesis, which is essential for real-life applications. Graphene oxide (GO) and reduced graphene oxide (rGO) are two graphene derivatives which not only compensate for the drawbacks of graphene but also introduce new properties. ${ }^{21-28}$ One of the main advantages of the GO derivatives is the ability to be easily dispersed in aqueous solution, thus broadening their usage in biological applications. ${ }^{29,30}$ rGO, which can be considered to be a "transitional material" between graphene and GO, offers both aqueous solubility and partial recovery of the conjugate system in a carbon network, making it a promising candidate for largescale synthesis in optoelectronics applications. ${ }^{31}$ Remarkably, the numbers of publications based on GO and rGO have also been rapidly increasing since 2009 (Fig. 1), following the same trend as graphene.

Among numerous composites and hybrids based on graphene and its derivatives, $10-20 \%$ of publications are about hybrids prepared from graphene (including GO and rGO) and nanoparticles (Fig. 2). On account of the unique and sizedependent optical, electronic, and catalytic properties of nanoparticles, combination of the beneficial characteristics of

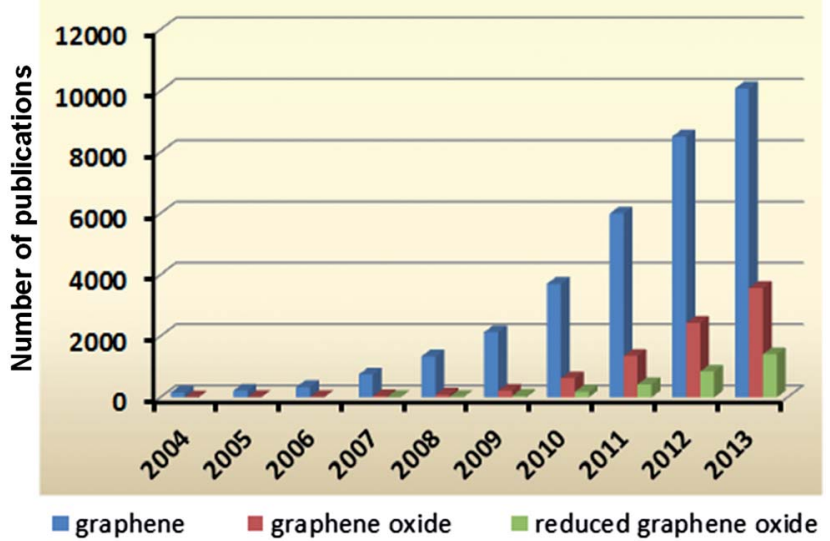

Fig. 1 Numbers of articles published based on graphene and its derivatives from 2004 till 2013 according to Scopus. The numbers were obtained using the key words "graphene", "graphene oxide" and "reduced graphene oxide", respectively.

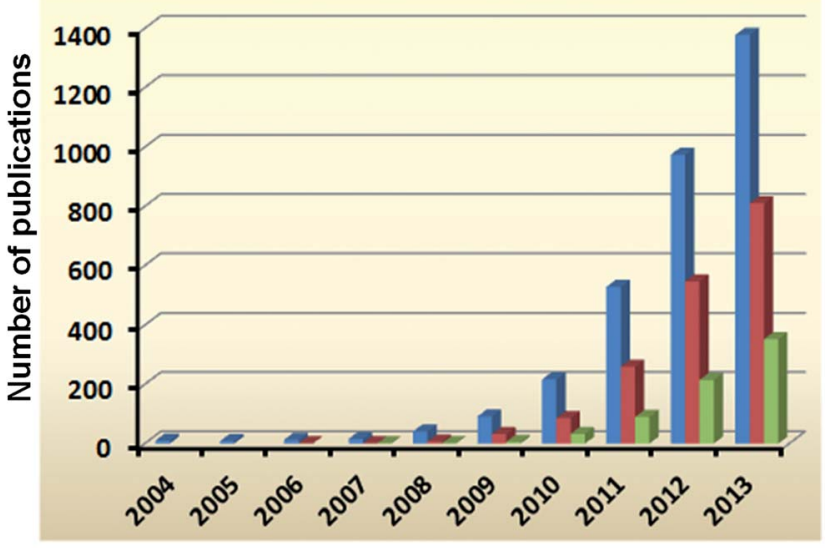

घ + nanoparticles $\square \mathrm{GO}+$ nanoparticles $\| \mathrm{rGO}+$ nanoparticles

Fig. 2 Numbers of articles published based on graphene/nanoparticle hybrids from 2004 till 2013 according to Scopus. The numbers were obtained using the key words of "graphene + nanoparticles", "graphene oxide + nanoparticles" and "reduced graphene oxide + nanoparticles", respectively.

graphene and nanoparticles can lead to the birth of novel hybrid materials. By integrating graphene with different types of nanoparticles such as quantum dots (QDs), metallic nanoparticles, and mesoporous silica nanoparticles, graphene-based hybrid materials present fascinating applications. This review first discusses the currently available synthetic techniques used to fabricate graphene/nanoparticle hybrids and their prospects in large-scale production. Then, different hybrids are highlighted selectively based upon their applications in electronics and nanomedicine. It is noteworthy that the roles of graphene in these two types of applications are slightly different. For electronic applications, graphene is utilized mainly for its high electron mobility and optical transparency, whereas in biological applications, it is used as a 2D platform or a wrapping sheet which can provide a large surface area for modifications. Electronic applications are reviewed covering the usefulness and outstanding performance of the aforementioned hybrids in transparent conducting thin films, and energy harvesting/ storage specifically in optoelectronics and lithium ion storage. For biological applications, the uses of representative hybrids in biosensing, bioimaging, and drug delivery as well as related prospects in this area are reviewed.

\section{Synthetic techniques and prospects in large-scale production}

Graphene/nanoparticle hybrids can be prepared by various synthesis methods. In this section, we categorize these synthesis techniques into two main classes based upon the structural morphologies of the final hybrids: (1) nanoparticles decorated on graphene or its derivatives, and (2) nanoparticles wrapped by graphene or its derivatives (Scheme 1). The main difference between these two classes is the relative size ratio between the nanoparticles and the lateral dimensions of 


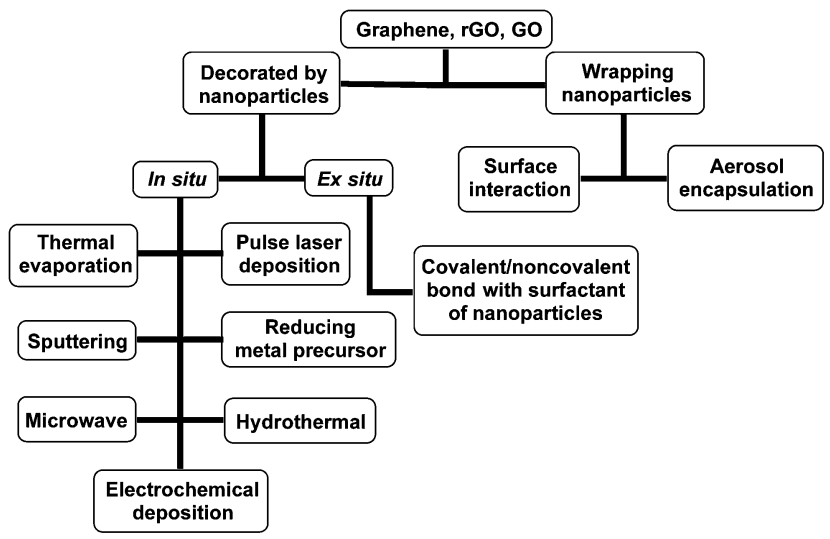

Scheme 1 Summary of various synthetic techniques for two classes of hybrids: (1) nanoparticles decorated on graphene or its derivatives and (2) nanoparticles wrapped by graphene or its derivatives.

graphene. When the size of the nanoparticles is in the range of a few nanometers to about 100 nanometers, the nanoparticles are small and can be easily decorated onto the graphene sheet. In contrast, when the particle size becomes comparable with graphene, the $2 \mathrm{D}$ sheet can be used to wrap around the particles, leading to the second type of hybrids.

\subsection{In situ decorating nanoparticles on graphene, GO, and rGO}

Deposition of nanoparticles on the inert surface of graphene is performed with the help of thermal evaporation, ${ }^{32}$ pulse laser deposition (PLD), ${ }^{33,34}$ or sputtering method. ${ }^{35}$ By using these techniques, defect-free graphene is preserved and the high electron mobility is maintained. Therefore, these hybrids normally exhibit good performance in nanocapacitors ${ }^{35}$ and counter electrodes. ${ }^{3,34}$ However, the requirements of high pressure $\left(\sim 10^{-4} \mathrm{~Pa}\right)$ and high temperature $\left(1260^{\circ} \mathrm{C}\right)$ associated with high cost and low synthesis efficiency have limited these techniques when applied in large-scale production. On the other hand, GO and rGO, which are readily dispersed in some solvents, have been used to prepare several hybrids using other versatile methods. Table 1 shows the in situ synthetic methods used to decorate nanoparticles onto graphene, rGO, and GO for various applications.

In situ reduction of metal salts followed by nucleation on graphene sheets is widely used to synthesize metal nanoparticle/GO and metal nanoparticle/rGO hybrids. The reductions of metal precursors, for example $\mathrm{HAuCl}_{4}, \mathrm{AgNO}_{3}$, and $\mathrm{K}_{2} \mathrm{PtCl}_{4}$, using reducing agents such as sodium citrate, ${ }^{36-38}$ sodium borohydride, ${ }^{39,40}$ ascorbic acid, ${ }^{41,42}$ and ethylene glycol ${ }^{43}$ were reported under facile and mild reaction conditions. The reaction mechanism is similar to conventional nanoparticle synthesis methods in solution and follows the steps of reduction, nucleation and particle growth. The covalent carbon units on the GO and rGO surface, such as alcohols $(\mathrm{C}-\mathrm{OH})$, carbonyl groups $(\mathrm{C}=\mathrm{O})$ and acids $(\mathrm{COOH})$, are responsible for the attachment of free metal ions through electrostatic interactions. Subsequently, the addition of reducing agent promotes the reduction of metal ions, enabling the growth of metal nanoparticles on the GO and rGO surface. ${ }^{37}$ By controlling the density of oxygen containing groups on the GO and rGO surface, one can easily tune the particle density in the hybrids. In addition, bimetallic hybrids can also be obtained by a two-step reduction. For example, the reduction of $\mathrm{H}_{2} \mathrm{PdCl}_{4}$ by formic acid followed by the reduction of $\mathrm{K}_{2} \mathrm{PtCl}_{4}$ by ascorbic acid yielded the graphene nanosheet/Pt-on-Pd nanodendrite hybrid, showing much higher catalytic activity than conventional Pt on $\mathrm{C}^{\mathbf{4 1}}$ Furthermore, hybrids with semiconducting nanoparticles such as CdSe can be easily achieved by the addition of rGO directly into the reaction solution during the synthesis of the CdSe nanoparticles. This approach dramatically enhances the photoinduced charge transfer process from the CdSe nanoparticles to rGO due to the direct anchoring of CdSe nanoparticles on rGO. ${ }^{44}$

As an alternative technique, the microwave method has been used as a source of energy to assist the reduction process. Metal nanoparticles (e.g. $\mathrm{Au}, \mathrm{Ag}, \mathrm{Cu}, \mathrm{Ru}$, and $\mathrm{Rh}$ ) and metal oxide nanoparticles (e.g. $\mathrm{Co}_{3} \mathrm{O}_{4}$ and $\mathrm{MnO}_{2}$ ) were decorated onto graphene and its derivatives with the help of rapid microwave irradiation. ${ }^{45-49}$ Compared with the abovementioned technique, however, the microwave assisted method has less control over the size and distribution of nanoparticles on the GO and rGO surface. Recently, by rapidly irradiating a suspension of rGO in ionic liquid 1-butyl-3-methylimidazolium tetrafluoroborate $\left(\mathrm{BMImBF}_{4}\right)$ and metal carbonyl precursors, particles with small and uniform sizes ( $\mathrm{Ru} 2.2 \pm 0.4 \mathrm{~nm}$ and $\mathrm{Rh} 2.8 \pm 0.5 \mathrm{~nm}$ ) were obtained with a dense distribution on the rGO surface. ${ }^{45}$ The procedure is notable for the precise control of size and the high density of particles on the rGO surface. Since metal carbonyl precursors of this method are hygroscopic and air sensitive, an inert atmosphere, i.e., glove box under argon, is required during the synthesis process.

The hydrothermal method is another commonly used approach to synthesize nanoparticles with a high crystallinity on a single layer surface of carbon. The process involves high temperature and high pressure, which induces the growth of nanocrystals and, at the same time, reduces GO to rGO. ${ }^{50-55}$ Typically, $\mathrm{Fe}_{3} \mathrm{O}_{4}$ nanoparticles with a diameter of $7 \mathrm{~nm}$ were densely and uniformly deposited on the rGO sheet. ${ }^{50}$ The reduction of GO by this process can be comparable to that by conventional methods. The $\mathrm{D} / \mathrm{G}$ intensity ratio of $\mathrm{rGO}$ in the aforementioned hybrids is $2.30: 1$, which is close to the ratio $(2.45: 1)$ of pristine graphene, indicating the recovery of the $\mathrm{sp}^{2}$ domain in the carbon network. ${ }^{50}$ In addition, on account of the facile, effective and scalable properties of this method, multicomponent upconversion luminescence nanocrystals, e.g. $\mathrm{NaYF}_{4}: \mathrm{Er}^{3+} / \mathrm{Yb}^{3+}$, were deposited onto rGO. The final hybrid emits bright green upconversion emissions under $980 \mathrm{~nm}$ of excitation, which is attractive for future solar cell applications. ${ }^{51}$

Electrochemical deposition has been employed to directly deposit nanoparticles on graphene-based substrates. This technique does not require a post-synthesis treatment including annealing and transferring. Due to their readiness to be functionalized on electrodes, the prepared hybrids are commonly used for biosensing applications. ${ }^{56-58}$ In general, the 
Table 1 Summary of in situ synthetic methods used to decorate nanoparticles onto graphene, rGO, and GO as well as their respective applications

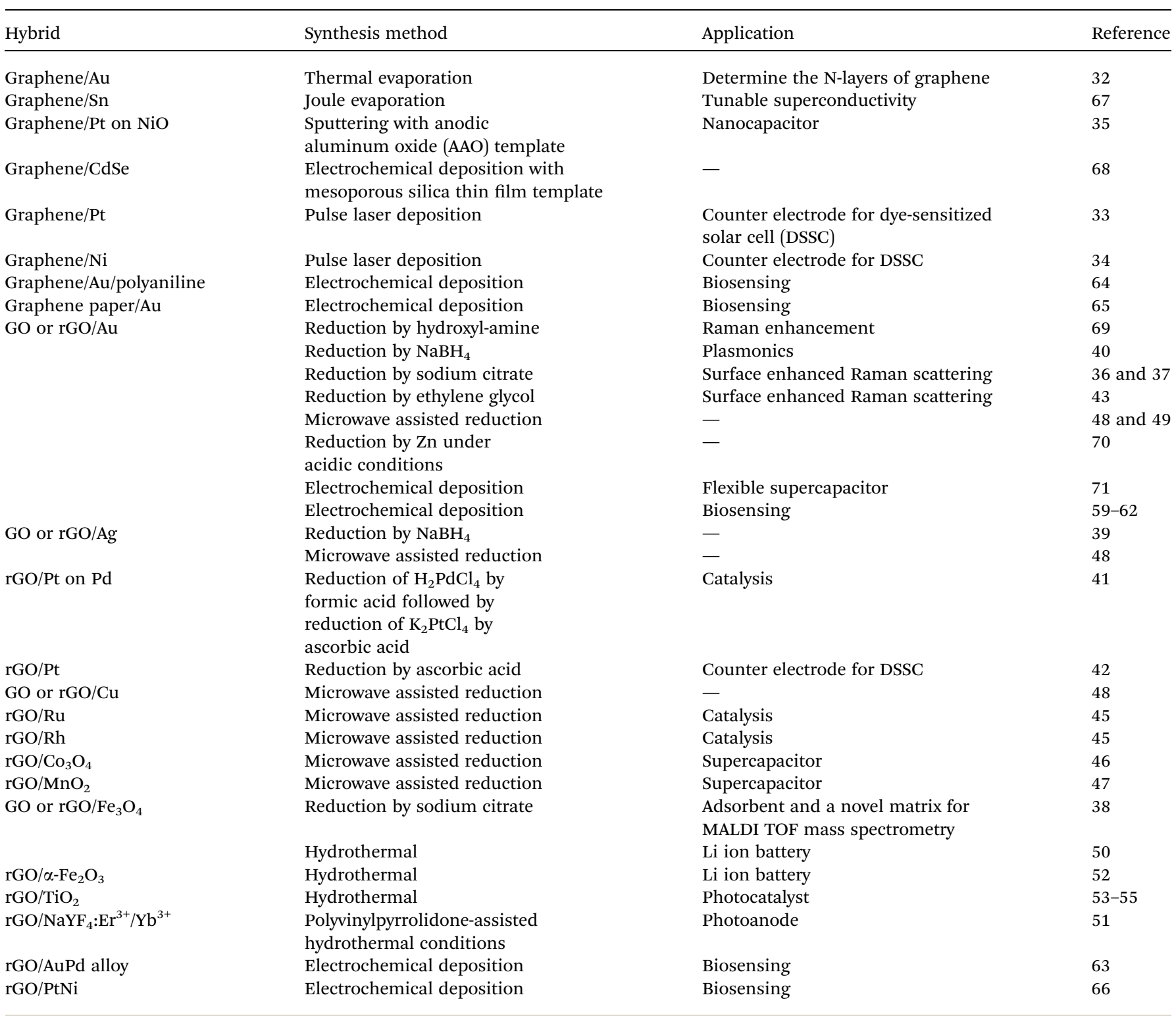

electrode active surface is coated with a graphene sheet followed by electrochemical deposition of nanoparticles and/or then modification with other bio-molecules, e.g. DNA, chitosan, antigen, or enzyme, for electrochemical sensing. These modified electrodes show dramatic enhancement in electrocatalytic activities towards various important electroactive compounds including ascorbic acid, uric acid, dopamine, and glucose..$^{59-66}$ This approach offers a versatile route to modify the working electrodes that can be finely tuned towards more selective, sensitive, highly reproducible and scalable biosensors, which are discussed in detail in Section 4.1.

\subsection{Ex situ decorating nanoparticles on graphene, GO, and rGO}

Mixing the pre-synthesized nanoparticles with graphene, rGO or GO sheet for the preparation of hybrids is an alternate method which offers good control over the size, shape, and functionality of the particles. A huge variety of nanoparticles with different morphologies such as spherical, cubic, octahedral, rod-like, nanowire, and hollow - to name just a few - have been widely explored, and their synthesis processes have been well developed in order to obtain homogenous size, shape, and surface functionalization. ${ }^{72-77}$ This development provides a solid platform for ex situ decorating nanoparticles on graphene sheets. By simply modifying or exchanging surfactants on nanoparticles, their surface can be easily modified to become adhesive to the graphene layer. The $\pi-\pi$ stacking and noncovalent bonding interactions between nanoparticles and the graphene surface are the main driving forces to anchor nanoparticles onto the 2D materials. For example, CdSe quantum dots (QDs) were encapsulated with conductive polymer polyaniline, and were decorated onto the graphene surface by $\pi-\pi$ interactions between the polymer shell and graphene 
conjugated system to achieve the QD@PANI-G hybrid. This approach preserves the well-defined spherical shape of the QDs and prevents further aggregation and degradation of CdSe in the hybrid..$^{78}$ Otherwise, the GO and rGO surface was modified with "linker molecules" ending with thiol or amine groups or "adhesive polymers" to immobilize nanoparticles. Bovine serum albumin (BSA) acting as an "adhesive polymer" has attracted much attention on account of its amphiphilic and biocompatible nature (Fig. 3). BSA-GO/rGO was reported as a template for the self-assembly of various nanoparticles (e.g. $\mathrm{Au}$, $\mathrm{Ag}, \mathrm{Pt}$, and Pd) on the GO and rGO surface. The loading density was easily controlled by changing the concentration of BSA and $\mathrm{NaCl}$ during the assembly process. ${ }^{79}$

\subsection{Nanoparticles wrapped by graphene and its derivatives}

An approach for ex situ integrating nanoparticles with graphene and its derivatives has been applied to nanoparticles with large sizes, typically ranging from a few hundred nanometers to several micrometers, in order to achieve graphene-wrapped nanoparticles. ${ }^{\mathbf{8 1 - 8 5}}$ GO- and rGO-encapsulated metal/metal oxide nanoparticles are commonly used as anode materials for lithium ion storage (Fig. 4). The introduction of GO and rGO layers can prevent the nanoparticles from aggregating and can accommodate large volume changes during the cycle processes, which overcame the main drawback in metal oxide anode materials. ${ }^{86-88}$ For instance, graphene-encapsulated $\mathrm{Co}_{3} \mathrm{O}_{4}$ is outstanding for its high and stable reversible capacity of about $1000 \mathrm{~mA} \mathrm{~h} \mathrm{~g}{ }^{-1}$, even after 130 cycles. This capacity was reported to be the highest among other conventional $\mathrm{Co}_{3} \mathrm{O}_{4}$ electrodes with a capacity range of $600-850 \mathrm{~mA} \mathrm{~h} \mathrm{~g}{ }^{-1} .^{80}$ This facile and low-cost procedure paves the way for large-scale production of graphene-based hybrid materials for energy storage. Furthermore, wrapping mesoporous nanoparticles by GO layers endows the hybrids with very useful properties. Recently, our group has developed GO-encapsulated mesoporous silica nanoparticles as a novel protective vessel for loaded dyes. ${ }^{89}$ The ionic interaction between the GO layers and amino groups on the silica nanoparticle surface is the driving force for hybrid formation, where the GO layer prevents the leakage of dyes loaded in the mesopores. The bioimaging application of this hybrid is discussed in detail in Section 4.2.

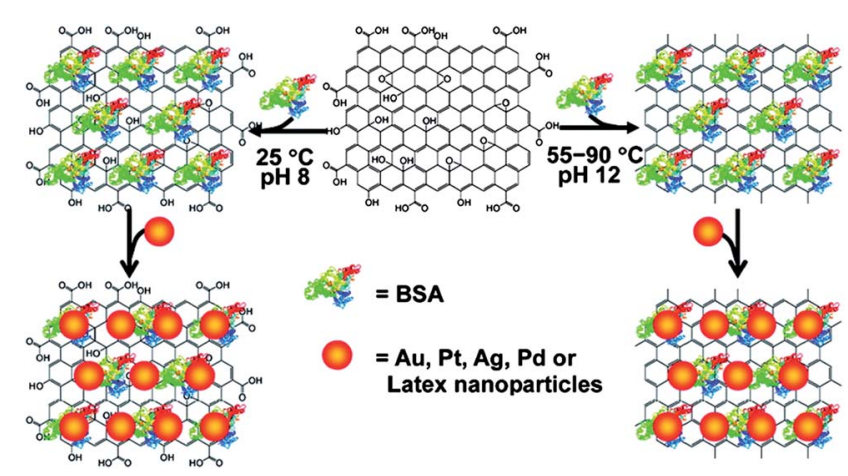

Fig. 3 Illustration of BSA-GO/rGO acting as a template for the assembly of $\mathrm{Au}, \mathrm{Ag}, \mathrm{Pt}$, and $\mathrm{Pd}$ nanoparticles. Reprinted with permission from ref. 79. Copyright 2010 American Chemical Society. a)
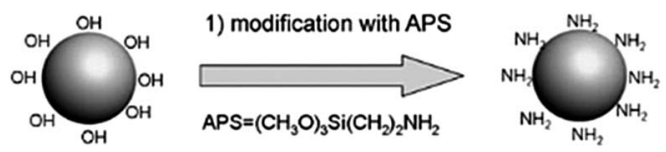

metal oxide

APS-modified metal oxide
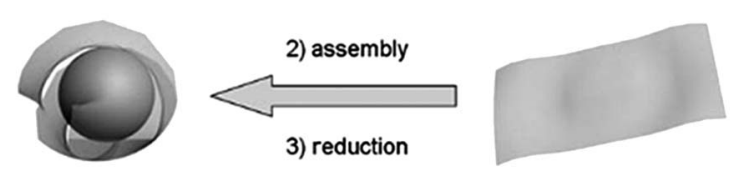

graphene-encapsulated metal oxide (GE-MO)
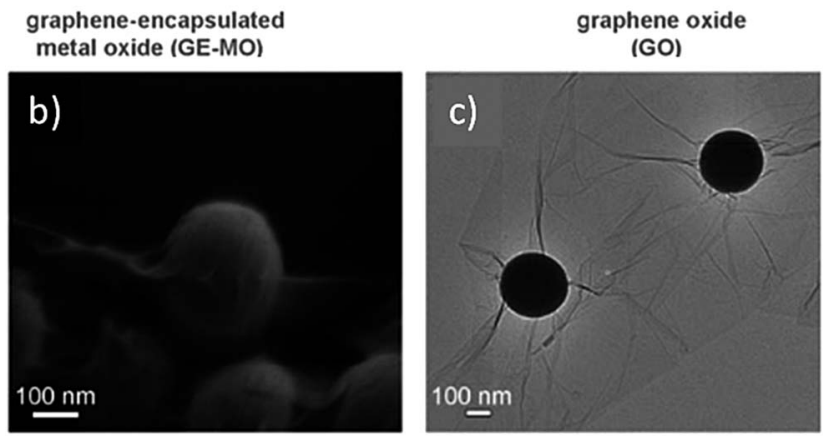

Fig. 4 (a) Fabrication of graphene-encapsulated metal oxide. (b and c) Typical SEM and TEM images of graphene-encapsulated silica spheres. Reprinted with permission from ref. 80. Copyright 2010 WILEY-VCH Verlag $\mathrm{GmbH} \& \mathrm{Co}$.

A different approach to produce wrapping hybrids using the aerosol encapsulation process has been reported. ${ }^{\mathbf{9 0 9}}$ This method is based on the colloidal interactions within drying microdroplets. It is noteworthy that the particle sizes in this case are smaller (a few to one hundred nanometers in diameter) than the above case. Thus, by using this method, several nanoparticles are encapsulated within "nanosacks" (Fig. 5). In contrast to the aforementioned method where opposite charges between $\mathrm{GO} / \mathrm{rGO}$ and nanoparticles are required to enhance the electrostatic interaction, this technique demonstrates very good encapsulation when the nanoparticles used possess the same charge as the GO surface, i.e., negative charges in neutral $\mathrm{pH}$. This technique is simple, yet has various advantages for the fabrication of multifunctional materials. The ability to encapsulate different types of material including ${ }^{90} \mathrm{rGO} / \mathrm{Au} / \mathrm{Fe}_{3} \mathrm{O}_{4}$ and $\mathrm{rGO} / \mathrm{BaTiO}_{3} / \mathrm{Fe}_{3} \mathrm{O}_{4}$ and to release the filled-cargos in a controlled manner are beneficial factors over conventional methods in biological applications.

\section{Electronics applications of graphene/nanoparticle hybrids}

Electronics applications have been the most popular usage of graphene-based materials since the successful fabrication of single layer graphene was reported in $2004 .^{20}$ The unusual electronic properties of graphene arise from the confinement of electrons in its 2D structure..$^{18,23,92-102}$ When considering 


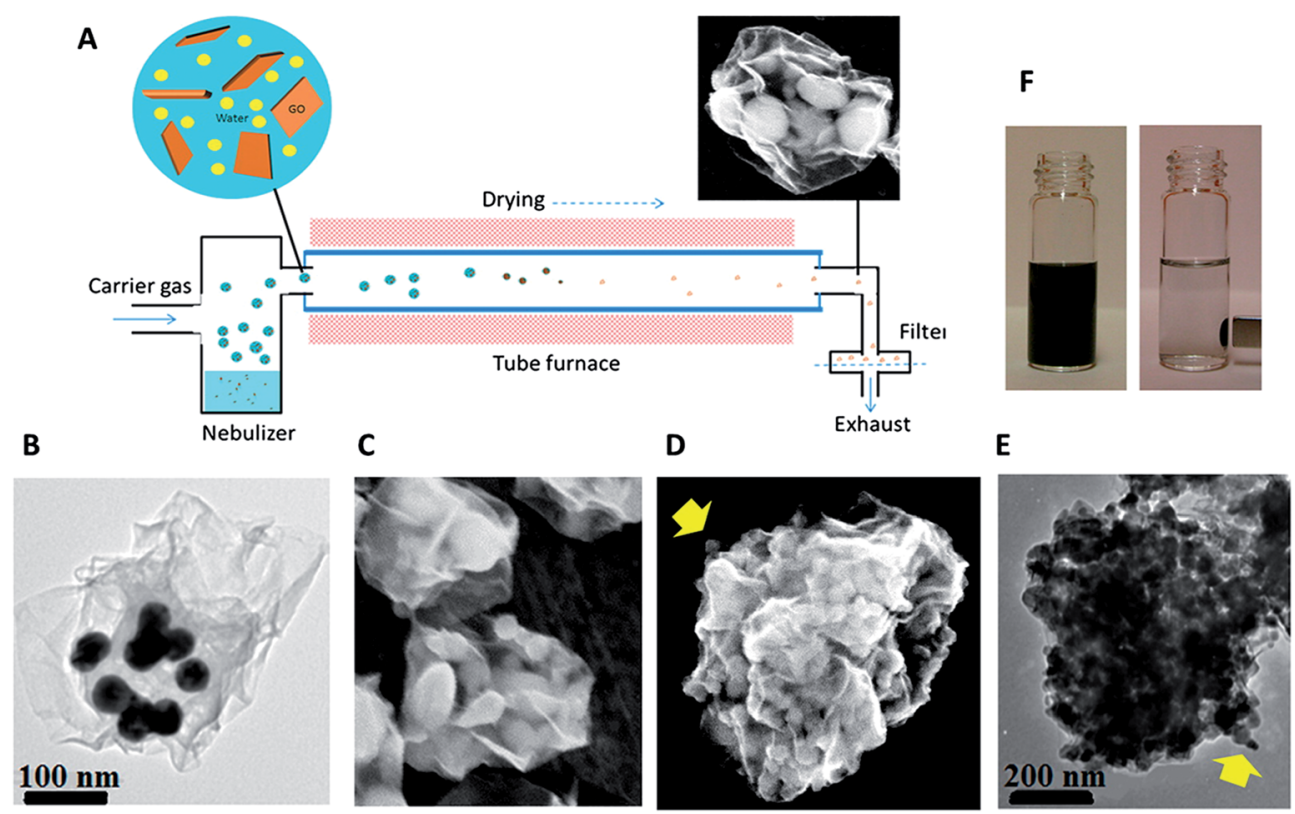

Fig. 5 (a) Continuous aerosol fabrication process leading to Ag-filled nanosacks. The nanosacks are filled with various types of nanoparticle including (b) tannic acid capped Au nanoparticles, (c) Si nanoparticles, (d and e) $\mathrm{Fe}_{3} \mathrm{O}_{4}$ nanoparticles, and (f) demonstration of the magnetic separation of $\mathrm{Fe}_{3} \mathrm{O}_{4}$-filled nanosacks in EtOH dispersion. Reprinted with permission from ref. 90. Copyright 2013 American Chemical Society.

graphene/nanoparticle hybrids in electronics applications, one may wonder whether the presence of nanoparticles obstructs or intervenes in the original distinctive properties of graphene. Can graphene/nanoparticle hybrids overcome the present obstacle of large-scale synthesis of pristine graphene? Are there any new applications that graphene/nanoparticle hybrids can bring to the family of graphene-based materials? In this section, we selectively discuss the current advances in graphene/nanoparticle hybrids in the fields of transparent conducting films (TCFs) and energy harvesting/storage in order to answer these questions.

\subsection{Transparent conducting films (TCFs)}

TCFs act as a window for light to pass through, and they show promising applications for modern devices such as touchscreens, electrodes on light emitting diodes and optoelectronic devices. ${ }^{103-106}$ Indium tin oxide (ITO) has been widely used as TCFs on account of its good conductivity $\left(10-20 \Omega \square^{-1}\right)$ and high transmittance $(>80 \%$ in the visible region of the solar spectrum).$^{107}$ However, the scarcity of the indium resource is the driving force for developing other sustainable materials. Thus, some alternatives to ITO have been reported, including polymers, ${ }^{\mathbf{1 0 8 - 1 1 0}}$ metal-polymer hybrids, ${ }^{\mathbf{1 1 1 - 1 1 3}}$ metals (metal nanowires and ultra-thin metal layers), ${ }^{\mathbf{1 1 4 - 1 1 7}}$ carbon nanotubes (CNTs), and graphene. ${ }^{118-123}$ Table 2 shows the sheet resistance, film transmittance and limitations of various materials used for TCFs. Among them, conducting polymers such as poly $(3,4-$ ethylenedioxythiophene) doped poly(styrene sulfonate) (PEDOT:PSS) have become the industry leader in the fabrication of TCFs. ${ }^{124-126}$ The PEDOT:PSS film was reported to have a sheet resistance as low as $115 \pm 10 \Omega \square^{-1}$ and a transmittance of
$85-90 \% .{ }^{127}$ The conductivity of this doped polymer could be enhanced by increasing the thickness of the polymer film. However, since film transparency follows the Beer-Lambert law, film thickness and transmittance are inversely related, leading to a low transmittance while conductivity is increased. In addition, CNTs were also fabricated into the nanotube networks, and can be used as a promising material to produce the TCFs. Nevertheless, the conductivity of the CNT networks still cannot be compared to ITO at high transmittance (Rs $=500$ $\Omega \square^{-1}$ at $T=85 \%$ ), and it greatly depends on the purity, diameter, defects, and metallicity of CNTs as well as the degree of dispersion. ${ }^{128}$

Theoretically, graphene possesses excellent conductivity and high transparency, and a $7 \mathrm{~nm}$ thick graphene layer was reported to have a sheet resistance of $1-10 \Omega \square^{-1} \cdot{ }^{139,140} \mathrm{Up}$ to the present time, two main methods are used to produce graphene films for TCFs: (1) chemically modified graphene (CMG) using rGO or exfoliated graphene from graphite, and (2) chemical vapor deposition (CVD) to grow graphene on metal foil substrates usually followed by a transferring or etching process to obtain free graphene films. The sheet resistance of CMG varies in a wide range from $10^{3}$ to $10^{7} \Omega \square^{-1}$ at $75-95 \%$ transmittance. ${ }^{129-132}$ On the other hand, CVD graphene generates a lower sheet resistance of a few hundred $\Omega \square^{-1}$ at $76-90 \%$ transmittance. ${ }^{8,9,133}$ Over the past few years, graphene/nanoparticle hybrids have been recognized for their enhanced performance in TCF applications with the significant advantage of possessing flexibility in comparison to rigid ITO. Deposition of metal nanoparticles such as Au nanoparticles (AuNPs) ${ }^{134}$ and PtNPs $^{135}$ onto CVD graphene has been reported to reduce the sheet resistance (to $45 \Omega \square^{-1}$ with AuNPs and $6.8 \Omega \square^{-1}$ with PtNPs) while still retaining a high transmittance level. However, 
Table 2 Comparison of the sheet resistance, film transmittance and limitations of various materials used for TCFs

\begin{tabular}{|c|c|c|c|c|}
\hline Material & Sheet resistance $\left(\Omega \square^{-1}\right)$ & Transmittance (\%) & Limitations & Reference \\
\hline ITO & $10-20$ & $\begin{array}{l}>80 \text { in visible region of solar } \\
\text { spectrum }\end{array}$ & $\begin{array}{l}\text { Scarcity of indium resource } \\
\text { increases the production } \\
\text { cost }\end{array}$ & 107 \\
\hline hcPEDOT:PSS & $115 \pm 10$ & $85-90$ & $\begin{array}{l}\text { Conductivity trades off with } \\
\text { transmittance }\end{array}$ & 127 \\
\hline Silver nanowires (AgNWs) & $13-33$ & 85 & - & 116 and 117 \\
\hline $\begin{array}{l}\text { Chemically modified } \\
\text { graphene (CMG) }\end{array}$ & $10^{3}$ to $10^{7}$ & $75-95$ & $\begin{array}{l}\text { Difficult to obtain } \\
\text { homogenous distribution of } \\
\text { graphene flake over large } \\
\text { area }\end{array}$ & $129-132$ \\
\hline $\begin{array}{l}\text { Single layer CVD graphene/ } \\
\text { AuNPs }\end{array}$ & 150 & 92 & - & 134 \\
\hline CVD graphene/PtNPs & 6.8 & - & - & 135 \\
\hline rGO/AgNPs & 8300 & 89.2 & High sheet resistance & 136 \\
\hline $\begin{array}{l}\text { Mixture of AgNPs/CNT and } \\
\text { AgNPs/graphene- } \\
\text { PEDOT:PSS }\end{array}$ & 50.3 & 79.73 & Low transmittance & 137 \\
\hline rGO/AuNPs/AgNWs & $26 \pm 1.04$ & 83 & - & 138 \\
\hline
\end{tabular}

the CVD method, which is not a solution-based synthetic process, is not preferable in large-scale production on account of its high processing cost.

Recently, many researchers have employed modified rGO sheets to produce graphene-based TCFs through solution methods. This approach facilitates large-scale synthesis, and at the same time, reduces production costs. Decorating rGO with pre-synthesized AgNPs capped with polyelectrolyte-poly(diallyldimethylammonium chloride) (PDDA) produced hybridbased TCFs with a high transmittance of $89.2 \%$ and a very high sheet resistance of $8300 \Omega \square^{-1} .^{136}$ When PEDOT:PSS was mixed with a hybrid of AgNPs/CNT and graphene/AgNPs, a lower sheet resistance of $50.3 \Omega \square^{-1}$ was obtained, while the transmittance was reduced to $79.73 \%{ }^{137}$ Achieving flexible TCFs with a low sheet resistance while retaining a high level of transmittance is currently a challenge in this research area. Recently, a threecomponent hybrid of rGO, silver nanowires (AgNWs) and AuNPs was reported with remarkably low sheet resistance $(26 \pm 1.04 \Omega$ $\left.\square^{-1}\right)$ and high transmittance $\left(T_{550}=83 \%\right)$, which can be comparable to the ITO materials. ${ }^{\mathbf{1 3 8}}$ Fabrication of this hybridbased thin film was achieved by simple spin coating of a AgNW dispersion and a GO/AuNP dispersion onto a glass followed by reducing the coated glass in hydrazine at $100{ }^{\circ} \mathrm{C}$ for $24 \mathrm{~h}$ (Fig. 6). It is noteworthy that the presence of the three different components improves the performance of the hybrid film by addressing the weaknesses of each component. Adding AuNPs significantly reduces the sheet resistance of the rGO films from $49.2 \pm 4.47 \Omega \square^{-1}$ for a single component rGO film to $28.6 \pm$
$1.43 \Omega \square^{-1}$ for rGO/AuNP film. Similarly, rGO acts as a 2D bridge between AgNWs, filling the gaps between AgNWs within the hybrid. Therefore, this hybrid shows a dramatic decrease in sheet resistance in comparison with its respective single component film (Fig. 6c). Furthermore, the hybrid also exhibits another distinguishable feature of antibacterial property, which can be a promising advantage for biomedical device applications.

\subsection{Energy harvesting/storage applications}

3.2.1. Optoelectronic devices. In this section, we discuss the light harvesting ability of graphene/nanoparticle hybrids. Increasing working efficiency and reducing production costs are always the goal in solar cell production. By combining quantum dots (QDs) and graphene-based materials, one can expect breakthrough performance from this type of hybrids in solar cell applications. QDs have been widely recognized for their ability to produce more than one exciton from a high-energy photon via the process of multiple exciton generation. However, the fast recombination of newly generated charge carriers decreases the performance of QDs in solar cells. In other words, capturing and transporting the photo-induced electrons as quickly as they are generated will greatly enhance the efficiency of QDs in energy harvesting devices. Previously, CNTs and fullerene have been reported to be able to capture and transport photo-induced electrons. ${ }^{\mathbf{1 4 1 - 1 4 4}}$ Compared to CNTs and fullerene, graphene is a better candidate for producing hybrids 


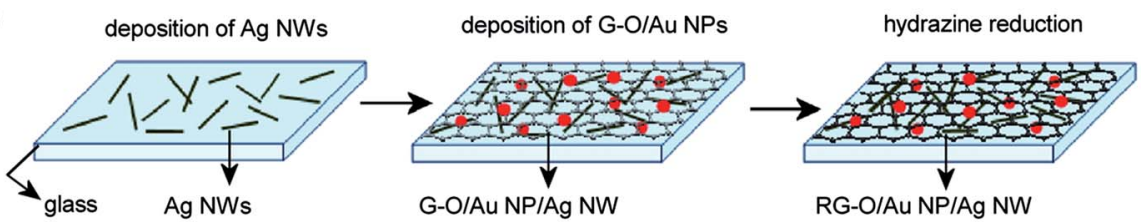

b)

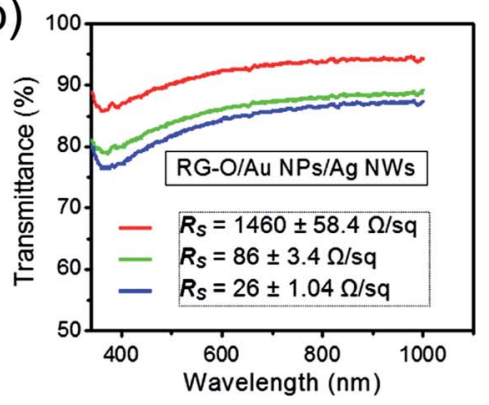

C)

\begin{tabular}{|c|c|c|c|}
\hline TCFs & $\begin{array}{c}\text { Conc. Ag NW } \\
\text { solution }\end{array}$ & $\begin{array}{c}T_{550} \\
\%\end{array}$ & $\begin{array}{l}R_{s} \\
\Omega / s q\end{array}$ \\
\hline \multicolumn{4}{|c|}{ Single component films } \\
\hline $\mathrm{Ag} \mathrm{NW}$ & $1.0 \mathrm{mg} / \mathrm{ml}$ & 96 & - \\
\hline $\mathrm{Ag} \mathrm{NW}$ & $2.0 \mathrm{mg} / \mathrm{ml}$ & 90 & $740 \pm 29.6$ \\
\hline $\mathrm{Ag} \mathrm{NW}$ & $2.5 \mathrm{mg} / \mathrm{ml}$ & 88 & $520 \pm 15.6$ \\
\hline RG-O & - & 94 & $49.2 \pm 1.96 \mathrm{k}$ \\
\hline RG-O/Au NP & - & 93 & $28.6 \pm 1.43 k$ \\
\hline \multicolumn{4}{|c|}{ Hybrid films } \\
\hline RG-O/Au NP/Ag NW & $1.0 \mathrm{mg} / \mathrm{ml}$ & 91 & $1460 \pm 58.4$ \\
\hline RG-O/Au NP/Ag NW & $2.0 \mathrm{mg} / \mathrm{ml}$ & 85 & $86 \pm 3.4$ \\
\hline RG-O/Au NP/Ag NW & $2.5 \mathrm{mg} / \mathrm{ml}$ & 83 & $26 \pm 1.04$ \\
\hline
\end{tabular}

Fig. 6 (a) Fabrication process of $\mathrm{rGO} / \mathrm{AuNP} / \mathrm{AgNW}$ film. AgNWs were spin coated on glass slides followed by coating GO/AuNP (0.5 $\mathrm{mg} \mathrm{mL}^{-1}$ ). The final hybrid was exposed to hydrazine vapor at $100^{\circ} \mathrm{C}$ for $24 \mathrm{~h}$. (b) Optical transmittance spectra of the hybrid films obtained with various concentrations of AgNW dispersion: (red) $1.0 \mathrm{mg} \mathrm{mL}^{-1}$, (green) $2.0 \mathrm{mg} \mathrm{mL}^{-1}$, and (blue) $2.5 \mathrm{mg} \mathrm{mL}^{-1}$. (c) $R_{\mathrm{s}}$ and $T_{550}$ data for single component and hybrid films. Reprinted with permission from ref. 138. Copyright 2012 American Chemical Society.

with QDs because (1) the high electron mobility within the graphene sheet enhances the charge transport of the hybrids, (2) the lower working function of graphene $(4.42 \mathrm{eV})^{145}$ in comparison with CNTs $(4.8 \mathrm{eV})^{143}$ facilitates charge transfer from the electron generator (QDs) to the electron acceptor (graphene), and (3) potential low-cost and large-scale production is possible.

One-step synthesis of $\mathrm{CdS}^{146}$ and $\mathrm{CdTe}^{147}$ nanoparticles on graphene was achieved by a hydrothermal process where GO was reduced concurrently with the formation of QDs. The synthetic method offers a direct contact between rGO and QDs, greatly enhancing the photo-response of the hybrids. A similar phenomenon was obtained with linker-free CdSe on graphene. ${ }^{44}$ The photosensitivity of $\mathrm{rGO} / \mathrm{CdSe}$, which was determined by the current under irradiation to the current in the dark, was recorded to be as high as $1700 \%$. Despite the high photoresponse, in situ synthesis of QDs on GO usually leads to an uneven distribution of nanoparticles on the rGO surface, thus increasing the inefficient loading of QDs on the graphene sheet. ${ }^{148}$ An alternate method to achieve a uniform distribution of QDs on the 2D carbon sheet is to simply mix the presynthesized QDs with graphene. Typically, the surface of QDs is modified to be conductive and able to facilitate the charge transfer process from QDs to the outer electron acceptor layer. Recently, a new graphene/QD hybrid was developed using conducting polymer (polyaniline) encapsulated QDs to enhance the stability of QDs on the graphene surface, preventing QDs from dissolution in aqueous solution. ${ }^{78}$ Moreover, the $\pi-\pi$ stacking interaction between the polymer shell and graphene layer endows a homogenous distribution of QDs on the graphene surface. This hybrid exhibits a good photo-response under light irradiation with various wavelengths of 405, 532, and $593.5 \mathrm{~nm}$. The photo-induced current increase was recorded for nine cycles, which indicated the stability of the hybrid system (Fig. 7). Similarly, mercapto-capped CdSe QD decorated graphene was used to fabricate a flexible photovoltaic cell. A power conversion efficiency of $0.6 \%$ and an incident photon to current conversion efficiency of $17 \%$ were achieved. ${ }^{149}$ Moreover, the introduction of the pyridine unit onto the QD surface was used as a surfactant to noncovalently anchor QDs on the graphene surface. ${ }^{150} \mathrm{~A}$ flexible and transparent film was fabricated using a simple filtration method to deposit the obtained hybrids onto cellulose membrane (Fig. 8). This approach opens up a new pathway for a facile, highly efficient and low cost production in future large-scale synthesis of graphene/nanoparticle hybrid-based optoelectronic devices. In addition, by changing the types of nanoparticle on the graphene sheet, a wide range of wavelengths could be detected. For instance, replacing the aforementioned QDs with PbS QDs ${ }^{151,152}$ generated a similar hybrid which was able to detect infrared light, whereas using $\mathrm{TiO}_{2}$ nanoparticles ${ }^{153,154}$ broadened the detection to the UV range.

3.2.2. Lithium ion storage. The lithium ion battery is now one of the most dominant power supply devices on account of its relatively high gravimetric and volumetric energy density. It is currently used as a convenient power source for portable electronic devices such as mobile phones, cameras, and laptops. With the rising demand for sustainable energy, the utilization of $\mathrm{Li}$ ion batteries in electric cars is expected. In order to meet the high demand, the specific capacity and cycle life of Li ion batteries need to be improved. Thus far, much effort has been made to enhance its performance. Oxides of transition metals such as tin, ${ }^{155-157}$ cobalt, ${ }^{158-161}$ nickel, ${ }^{162,163}$ copper, ${ }^{164,165}$ manganese, ${ }^{162,166,167}$ iron, ${ }^{160,168-172}$ and molybdenum ${ }^{173-177}$ have been employed as anode materials in Li ion batteries, which can provide high specific capacity. However, the significant change in volume of metal oxides occurring during the cycling processes has led to the pulverization of these electrodes, rapidly reducing the capacity. ${ }^{80}$ In order to overcome this drawback, carbonaceous materials have been used as buffer 

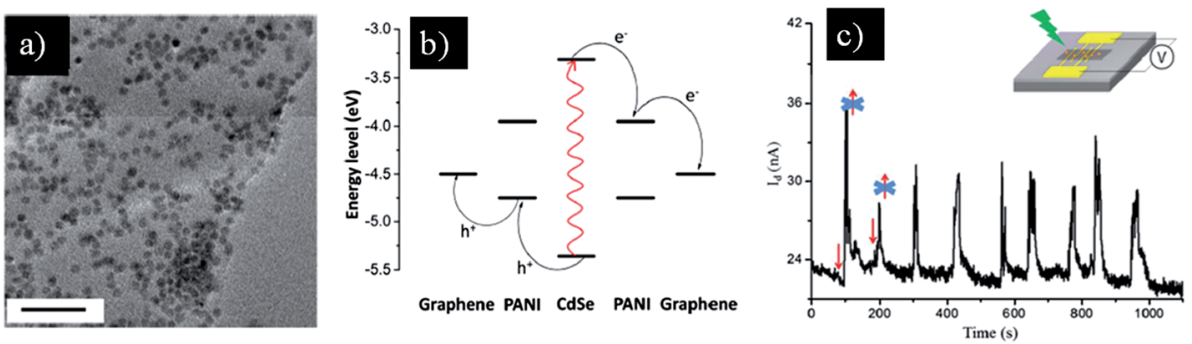

Fig. 7 (a) TEM image of graphene hybrid coated with polyaniline-encapsulated CdSe QDs, scale bar is $50 \mathrm{~nm}$. (b) Illustration of the charge transfer process within the hybrid. Light excites the CdSe electron to its LUMO where it is transferred to LUMO of surrounding polyaniline, followed by transfer to the graphene layer. Meanwhile, the holes are transferred from the CdSe LUMO to the polyaniline LUMO and then to graphene. (c) Current-versus-time curve of the hybrid-based device under $532 \mathrm{~nm}$ wavelength of light with an irradiation time interval of $30 \mathrm{~s}$ for nine cycles. The inset shows the device configuration for the measurements. Reprinted with permission from ref. 78 . Copyright 2013 American Chemical Society.
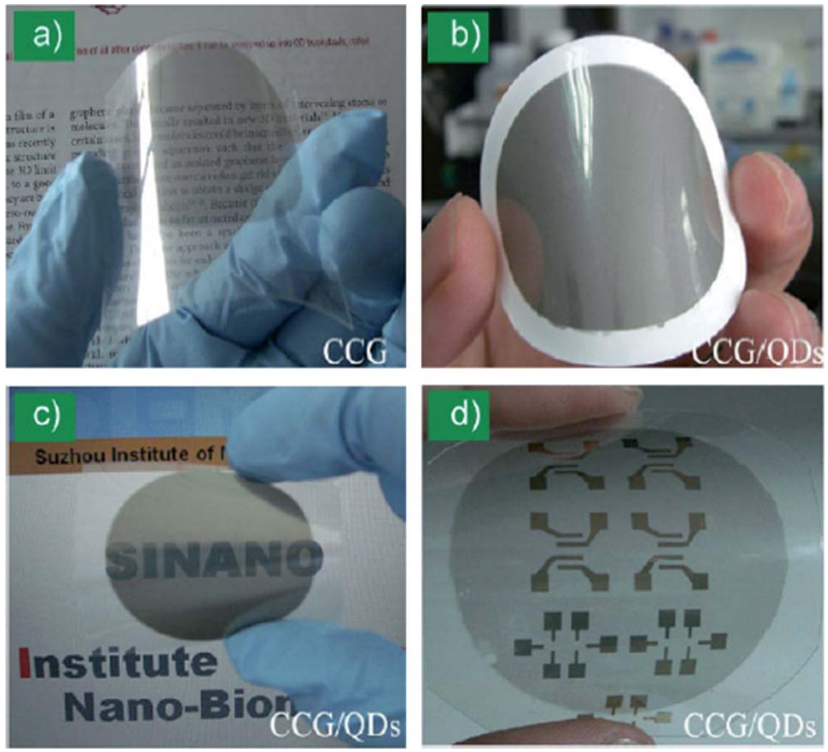

Fig. 8 (a) A transferred chemically converted graphene film on polyethylene terephthalate (PET) substrate. (b) A filtered graphene/CdSe hybrid on mixed cellulose ester membrane. (c) A transferred graphene/ CdSe hybrid-based film on plastic substrate. (d) A graphene/CdSe hybrid-based film with patterned electrodes on a flexible and transparent plastic substrate. Reprinted with permission from ref. 150 Copyright 2010 WILEY-VCH Verlag GmbH \& Co.

materials due to their tensile and conductive properties. Among carbon-based materials (amorphous carbon, CNTs, graphite, and graphene), graphene and its derivatives are the most promising materials to be used in conjunction with metal oxides for enhancing the performance of $\mathrm{Li}$ ion batteries. Wrapping $\mathrm{Co}_{3} \mathrm{O}_{4}$ nanoparticles with $\mathrm{GO}$ has dramatically enhanced the specific capacity (1100 $\mathrm{mA} \mathrm{h} \mathrm{g}^{-1}$ at a low current density of $74 \mathrm{~mA} \mathrm{~g}^{-1}$ ) of hybrid-based electrodes in comparison with the highest value $\left(600-850 \mathrm{~mA} \mathrm{~h} \mathrm{~g}{ }^{-1}\right)$ achieved using $\mathrm{Co}_{3} \mathrm{O}_{4}$-based electrodes. ${ }^{80}$ Moreover, the $\mathrm{Co}_{3} \mathrm{O}_{4} / \mathrm{GO}$ hybridbased electrode exhibits a high and stable reversible capacity of about $1100 \mathrm{~mA} \mathrm{~h} \mathrm{~g}^{-1}$ after the first 10 cycles and $1000 \mathrm{~mA} \mathrm{~h} \mathrm{~g}^{-1}$ after 130 cycles (about 94\% retention). Interestingly, simple mixing of $\mathrm{Co}_{3} \mathrm{O}_{4}$ nanoparticles with $\mathrm{GO}$ by mechanical blending also yields an enhancement in specific capacity of the electrode $\left(832 \mathrm{~mA} \mathrm{~h} \mathrm{~g}^{-1}\right.$ ), but a decrease in the retention rate (only $67 \%$ retention after 30 cycles) compared to that of the wrapping hybrid-based electrode. These phenomena confirm the superiority of graphene/nanoparticle hybrids in Li ion batteries, i.e., (1) the presence of GO facilitates the volume change of metal oxides during the charge-discharge cycles, preventing the pulverization of electrodes and increasing the retention rate of the hybrid-based anode, (2) the graphene sheet has acted as a blanket wrapping around nanoparticles to prevent the aggregation of nanoparticles, and (3) the GO layers connect and maintain the electro-conductivity of the hybrid-based electrodes.

In another approach, $\mathrm{Mn}_{3} \mathrm{O}_{4}$ nanoparticles, possessing a theoretical capacity of $936 \mathrm{~mA} \mathrm{~h} \mathrm{~g}^{-1}$, which is slightly higher than that of $\mathrm{Co}_{3} \mathrm{O}_{4}$, were grown directly onto the GO sheet via a two-step solution phase reaction. ${ }^{178}$ The hydrolysis of $\mathrm{Mn}\left(\mathrm{CH}_{3} \mathrm{COO}\right)_{2}$ in the GO suspension followed by hydrothermal reaction at $180^{\circ} \mathrm{C}$ for 10 $\mathrm{h}$ produced a uniform distribution of $\mathrm{Mn}_{3} \mathrm{O}_{4}$ nanoparticles (10-20 $\mathrm{nm}$ in diameter) on the rGO layers (Fig. 9). This hybrid was used as an anode material, and an unprecedented high specific capacity among Mn-based anodes of nearly $900 \mathrm{~mA} \mathrm{~h} \mathrm{~g}^{-1}$ at $40 \mathrm{~mA} \mathrm{~g}^{-1}$ was recorded, which could still be retained as high as $780 \mathrm{~mA} \mathrm{~h} \mathrm{~g}^{-1}$ at the higher current density of $400 \mathrm{~mA} \mathrm{~g}^{-1}$. The striking enhancement in capacity ( $730 \mathrm{~mA} \mathrm{~h} \mathrm{~g}{ }^{-1}$ after 40 cycles) as well as the stability of the anode were attributed to the homogenous morphology and distribution of $\mathrm{Mn}_{3} \mathrm{O}_{4}$ nanoparticles on the rGO
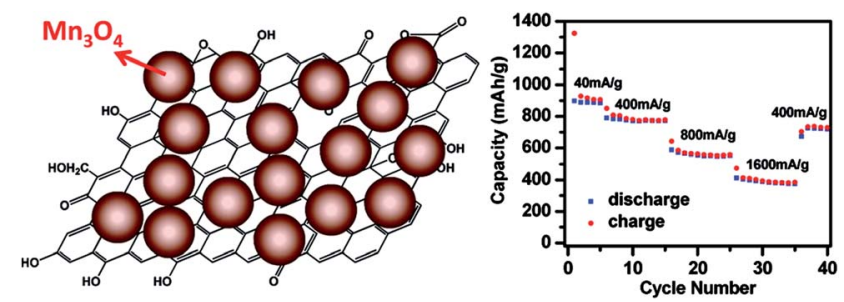

Fig. 9 Illustration of $\mathrm{Mn}_{3} \mathrm{O}_{4}$ nanoparticles on a graphene sheet and cycling performance of the graphene/ $\mathrm{Mn}_{3} \mathrm{O}_{4}$ hybrid-based anode at various current densities. Reprinted with permission from ref. 178. Copyright 2010 American Chemical Society. 
sheets. Other hybrids prepared by a similar approach have also been reported to demonstrate the same trend of enhancement in both specific capacity and stability of $\mathrm{Li}$ ion anodes, including graphene $/ \mathrm{Fe}_{3} \mathrm{O}_{4},{ }^{179}$ graphene $/ \alpha-\mathrm{Fe}_{2} \mathrm{O}_{3},{ }^{180}$ graphene $/ \mathrm{Si},{ }^{181}$ and graphene $/ \mathrm{SnO}_{2} \cdot{ }^{182}$ Table 3 provides a comparison in terms of the capacity and cycle performance of several graphene/nanoparticle hybrid-based anodes in Li ion batteries.

By controlling the morphology of metal oxides, one can produce anode materials with even better performance compared with nanoparticle-based hybrids. Nanosheets such as $\mathrm{CuO},{ }^{183} \mathrm{NiO}^{184}$ and $\mathrm{MoS}_{2}$ (ref. 186) are representative examples for fabricating anode materials with high capacity and stability. The intercalation of NiO nanosheets $(0.5-2 \mu \mathrm{m}$ in size and $30-$ $50 \mathrm{~nm}$ in thickness) between graphene sheets prevents the restacking of the $\mathrm{sp}^{2}$ carbon layers with much better capability than nanoparticles, thus preserving the intrinsic high electron mobility of graphene. ${ }^{184} \mathrm{~A}$ high capacity of $872 \mathrm{~mA} \mathrm{~h} \mathrm{~g}^{-1}$ at a high current rate of $718 \mathrm{~mA} \mathrm{~g}^{-1}$ and a high retention rate of 97.6\% was obtained using this type of sheet-on-sheet anode material (Fig. 10).

\section{Biological applications of graphene/nanoparticle hybrids}

The bio-nano interface is a promising study area in nanoscience. If the high electron mobility of graphene makes it a great material in electronics applications, the biocompatibility on the other hand enhances its use in biological applications. Many reports have shown significant advantages of graphene-based materials in biological applications such as light-induced therapeutics, ${ }^{\mathbf{1 8 7}}$ tissue and genetic engineering, ${ }^{188}$ and drug delivery. ${ }^{189}$ In addition, different types of nanoparticles including noble metal, ${ }^{\mathbf{1 9 0}}$ iron
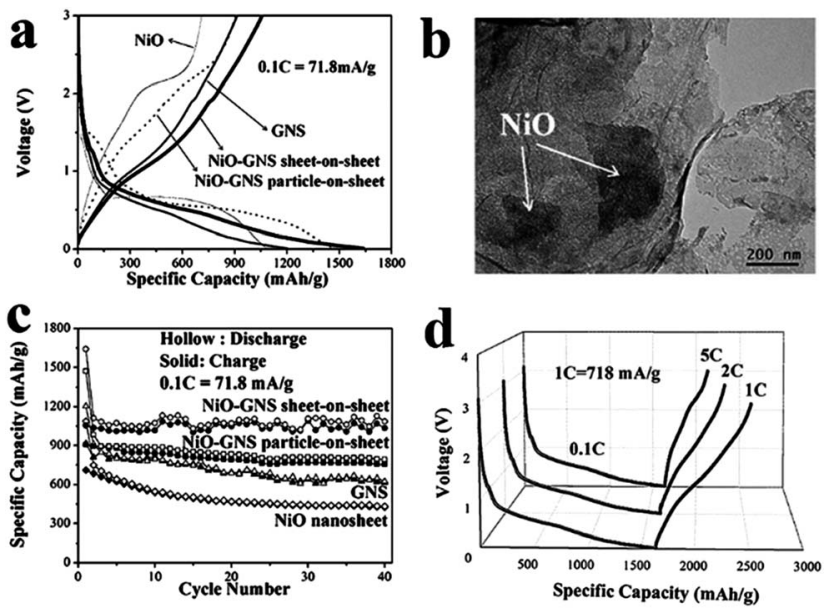

Fig. 10 (a) Electrochemical performance of different types of anode materials: the first cycle of charge-discharge-charge curves of anodes prepared from $\mathrm{NiO}$, graphene nanosheet (GNS), NiO nanoparticles on GNS, and $\mathrm{NiO}$ nanosheets on GNS at $71.8 \mathrm{~mA} \mathrm{~g}^{-1}$. (b) TEM image of an anode prepared from $\mathrm{NiO}$ nanosheets on GNS after 40 cycles. (c) Cycling performance of an anode prepared from $\mathrm{NiO}$ nanosheets on GNS at $71.8 \mathrm{~mA} \mathrm{~g}^{-1}$. (d) The first cycle of dischargecharge curves for an anode prepared from $\mathrm{NiO}$ nanosheets on GNS at large currents of 718, 1436, and $3590 \mathrm{~mA} \mathrm{~g}^{-1}$. Reprinted with permission from ref. 184. Copyright 2011 The Royal Society of Chemistry.

oxide ${ }^{191-194}$ upconversion, ${ }^{195}$ organic, ${ }^{196-198}$ and mesoporous/ hollow silica ${ }^{199-209}$ nanoparticles have been studied extensively for their uses in bioimaging, biosensing, drug delivery, etc. Thus, rational combination of these two kinds of nanomaterial may generate synergy effects to make pronounced impacts in biological applications.

Table 3 Comparison of the capacity and cycle performance of several graphene/nanoparticle hybrid-based anodes in Li ion batteries

\begin{tabular}{|c|c|c|c|c|}
\hline & $\begin{array}{l}\text { Specific capacity } \\
\left(\mathrm{mA} \mathrm{h}^{-1}\right)\end{array}$ & $\begin{array}{l}\text { Current density } \\
\left(\mathrm{mA} \mathrm{g}^{-1}\right)\end{array}$ & $\begin{array}{l}\text { Retained capacity }\left(\mathrm{mA} \mathrm{h} \mathrm{g}^{-1}\right) \\
\text { after a number of cycles }\end{array}$ & Ref. \\
\hline Graphene $/ \mathrm{Co}_{3} \mathrm{O}_{4}$ & 1100 & 74 & 1000 after 130 cycles & 80 \\
\hline & 780 & 400 & 730 over 40 cycles & \\
\hline \multirow[t]{2}{*}{ Graphene $/ \mathrm{Fe}_{3} \mathrm{O}_{4}$} & 1120 & $0.2 \mathrm{C}$ & 800 cycles without capacity decay & 179 \\
\hline & 860 & $4 \mathrm{C}$ & & \\
\hline \multirow[t]{3}{*}{ Graphene/sheet like $\mathrm{CuO}$} & 981 & 700 & - & 183 \\
\hline & 925 & 1400 & 532 over 100 cycles & \\
\hline & 846 & 3500 & - & \\
\hline \multirow[t]{3}{*}{ Graphene/nanosheet NiO } & 1056 & 71.8 & 1031 over 40 cycles & 184 \\
\hline & 872 & 718 & - & \\
\hline & 657 & 1436 & - & \\
\hline & 810 & 50 & & \\
\hline Graphene/SnO ${ }_{2}$ & 687 & 50 & 650 over 30 cycles & 182 \\
\hline Graphene/nanosheet $\mathrm{MoS}_{2}$ & 1200 & - & Stable over 100 cycles & 186 \\
\hline
\end{tabular}




\subsection{Electrochemical biosensing}

Graphene/nanoparticle hybrids have had an enormous impact in electrochemical biosensing applications. These hybrids possess several properties which dramatically enhance the performance of the sensing electrodes in terms of their sensitivity, selectivity, and range of detection. First, graphene modified electrodes normally have an enhanced active surface area in comparison to conventional electrodes made from graphite. Owing to the $2 \mathrm{D}$ structure of graphene, the entire carbon network is exposed to the outer environment, providing more sites for the detecting molecules to anchor. Moreover, the high edge-to-base ratio in graphene also offers more active sites, which was reported to accelerate the electron transfer between the electrode and analyte molecules. ${ }^{210,211}$ The biocompatibility of graphene is another advantage brought to the graphenebased hybrids for in situ biosensing. ${ }^{30}$ However, biological species - for example, enzymes - normally have poor contacts between their active sites and the electrode surface on account of the embedded nature of their active sites within the thick insulating protein shell. The presence of nanoparticles on the surface of graphene plays an important role as an electron transfer mediator between the redox center in proteins and the graphene layers. ${ }^{212}$ Furthermore, metal nanoparticles also lower the overpotentials, hence increasing the sensitivity of the sensing electrodes. Table 4 summarizes several hybrids of nanoparticles on graphene sheets for electrochemical sensing applications. Single metal nanoparticles, such as $\mathrm{Au},{ }^{\mathbf{2 1 3 , 2 1 4}} \mathrm{Ag},{ }^{\mathbf{2 1 5}}$ $\mathrm{Pt}^{216,217}$ and $\mathrm{Pd}^{218}$ nanoparticles, as well as bi-metallic nanoparticles, e.g. $\mathrm{Au}-\mathrm{Pd},{ }^{63} \mathrm{Au}-\mathrm{Fe}_{3} \mathrm{O}_{4},{ }^{219} \mathrm{Au}-\mathrm{TiO}_{2},{ }^{220}$ and $\mathrm{Ag}-\mathrm{Pd}^{221}$ nanoparticles, were successfully decorated on graphene sheets and demonstrated their usefulness in sensing various types of biomarker. Size selective Pt nanoparticles (mean diameter of 1.7 $\mathrm{nm}$ ) decorated homogenously on the graphene layer have shown the simultaneous detection of ascorbic acid (AA), dopamine (DA), and uric acid (UA) by cyclic voltammetry and differential pulse voltammetry (DPV). The optimized immobilization of size-selected Pt nanoparticles was believed to widen the electrochemical potential difference between the three analytes, thus enabling their concurrent detection. ${ }^{217}$ Recently, a double signal amplification platform was developed based on a hybrid of ferrocene thiolate stabilized $\mathrm{Fe}_{3} \mathrm{O}_{4}$ @Au nanoparticles with graphene sheets. ${ }^{222}$ The hybrid obtained has shown a wider linear range for all the three analytes and a higher detection limit in comparison to the aforementioned hybrids (Table 4).

Glucose sensing is another common application of graphene/nanoparticle hybrids. Several hybrids have been reported with enhanced performance towards glucose detection with a wide linear range (graphene/Pd with a linear range of $10 \mu \mathrm{M}$ to $5 \mathrm{mM}$ ), ${ }^{218}$ low detection limit (chitosan-graphene/PdNPs with a detection limit of $0.2 \mu \mathrm{M}$ and signal-to-noise ratio of 3$)^{230}$ and high sensitivity (rGO/Au/PdNPs with a sensitivity of $266.6 \mu \mathrm{A}$ $\left.\mathrm{mM}^{-1} \mathrm{~cm}^{-2}\right) .{ }^{63}$ The presence of nanoparticles in the hybrids further shows their significance in DNA detection. The surface of the graphene/AuNP electrode could be easily modified by thiolated-DNA (probe-DNA) through strong $\mathrm{Au}-\mathrm{S}$ bonding
(Fig. 11). ${ }^{62}$ When the target DNA completely hybridizes with the probe DNA, the electron is transferred from the electrode surface to methylene blue to catalyze $\left[\mathrm{Fe}(\mathrm{CN})_{6}\right]^{3-}$, thus showing a reduction peak in the DPV measurements. ${ }^{62}$ If the target DNA is mismatched or the GO surface is modified by the probe DNA through non-covalent bonding, there is no obvious reduction peak observed due to the termination of electron transfer. The target DNA detected using this hybrid-based electrode can be as low as $100 \mathrm{fM}$ in concentration. It is noteworthy that the electrodeposition technique was employed for decorating AuNPs onto GO, which is believed to be a promising method for largescale fabrication.

Based upon the same working mechanism, other multicomponent systems have been developed for large biospecies detection, such as prostate specific antigen (PSA), ${ }^{219}$ thrombin, ${ }^{230}$ and transferrin. ${ }^{234}$ Recently, GO/nanoparticle hybrids have paved the way for in situ detection of living cells, which provided a simple, rapid, label-free, and cell-based sensor for probing the toxicity of cells. For instance, living pheochromocytoma (PC-12) cells were deposited on top of a GO/AuNP-modified glassy carbon electrode by a simple drop casting method (Fig. 12). ${ }^{60}$ The electrochemical behavior of living cells was characterized by cyclic voltammetry at different scan rates, DPV, and electrochemical impedance spectra (EIS).

\subsection{Bioimaging, treatment and drug delivery}

Bio-nanomaterials offer great platforms to interact with biological systems in a desired pathway. By rationally controlling the size, shape and surface chemistry of nanomaterials, tasks that were considered impossible only 20 years ago can now be achieved. In the fields of bioimaging, treatment and drug delivery, numerous reports have illustrated the potential applications of nanomaterials. In particular, by integrating the graphene sheet with nanoparticles, one can expect a novel type of multifunctional biomaterial for theranostics. Since graphene/nanoparticle hybrids usually bring the property of synergy, in this section, we selectively highlight recent outstanding achievements with different types of graphene/nanoparticle hybrids and their respective applications in these fields.

Decorating the graphene sheet with some nanocrystals brings about various applications in bioimaging. The GO/AuNP hybrid has shown useful applications in Raman imaging. The presence of AuNPs on the graphene surface remarkably enhances the Raman signal of GO by a surface enhanced Raman scattering (SERS) effect, even in aqueous solutions. HeLa 229 cells incubated with the GO/AuNP hybrid exhibit a much stronger Raman signal than those cells incubated with pristine GO. ${ }^{36}$ Otherwise, when fluorescent nanoparticles are anchored on the graphene surface, the hybrids obtained can be used as fluorescent probes for biomedical targeting and imaging. After PEGylation of zinc-doped $\mathrm{AgInS}_{2}$ nanoparticle-decorated GO sheets, the final hybrid exhibits four different emission colors including green, yellow, orange and red. ${ }^{240}$ In vitro cellular fluorescent imaging on NIH/3T3 cell lines was successfully demonstrated using this hybrid, showing the feasibility of applying the hybrid for biomedical cellular imaging. 
Table 4 Various graphene/nanoparticle hybrid-based electrodes for electrochemical sensing applications

\begin{tabular}{|c|c|c|c|c|c|}
\hline Hybrid & Biomarker & 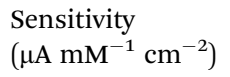 & $\begin{array}{l}\text { Detection limit } \\
(S / N=3)\end{array}$ & Linear range & Ref. \\
\hline PDDA@AuNP-graphene/MWCNT & Glucose & 29.72 & $4.8 \mu \mathrm{M}$ & $5-175 \mu \mathrm{M}$ & 223 \\
\hline & - & - & - & $2-14 \mathrm{mM}$ at $0.5 \mathrm{~V}$ & \\
\hline \multirow[t]{2}{*}{ Graphene/Pt } & AA & 0.3457 & $0.15 \mu \mathrm{M}$ & $0.15-34.4 \mu \mathrm{M}$ & 217 \\
\hline & DA & 0.9695 & $0.03 \mu \mathrm{M}$ & $0.03-8.13 \mu \mathrm{M}$ & \\
\hline Graphene/Pd & Glucose & - & $1 \mu \mathrm{M}$ & $10 \mu \mathrm{M}$ to $5 \mathrm{mM}$ & 218 \\
\hline $\mathrm{GO} / \mathrm{Ag} / \mathrm{SiO}_{2}$ & Glucose & - & $4 \mu \mathrm{M}$ & $0.1-260 \mathrm{mM}$ & 225 \\
\hline Chitosan-graphene/PdNPs & Glucose & 31.2 & $0.2 \mu \mathrm{M}$ & $1 \mu \mathrm{M}$ to $1 \mathrm{mM}$ & 226 \\
\hline $\mathrm{rGO} / \mathrm{Au} / \mathrm{PdNPs}$ & Glucose & 266.6 & $6.9 \mu \mathrm{M}$ & Up to $3.5 \mathrm{mM}$ & 63 \\
\hline Tyr-AuNP/PASE-GO/SPE & Catechol & - & $0.024 \mu \mathrm{M}$ & $0.083-23 \mu \mathrm{M}$ & 227 \\
\hline Graphene/AuNP-TiO ${ }_{2}$ & ProGRP & - & $3 \mathrm{pg} \mathrm{mL^{-1 }}$ & $10-500 \mathrm{pg} \mathrm{mL} \mathrm{m}^{-1}$ & 220 \\
\hline rGO/hollow CoPt & Thrombin & - & $0.34 \mathrm{pM}$ & $1-50000 \mathrm{pM}$ & 230 \\
\hline CVD graphene/AuNPs & Glucose & - & - & - & 213 \\
\hline Graphene/chitosan-PtNPs/AuNPs & Erythromycin & - & $0.023 \mu \mathrm{M}$ & $0.07-90 \mu \mathrm{M}$ & 231 \\
\hline Graphene/AuNPs & Cholesterol & 0.00314 & $0.05 \mu \mathrm{M}$ & $0.05-0.35 \mathrm{mM}$ & 214 \\
\hline Graphene paper/PtAu- $\mathrm{MnO}_{2}$ & Glucose & 58.54 & $0.02 \mathrm{mM}$ & $0.1-30 \mathrm{mM}$ & 232 \\
\hline GO/AgNPs & Tryptophan & - & $2 \mathrm{nM}$ & - & 215 \\
\hline $\mathrm{Cu}_{2} \mathrm{O}$ wrapped by graphene & Glucose & - & $3.3 \mu \mathrm{M}$ & $0.3-3.3 \mathrm{mM}$ & 233 \\
\hline $\mathrm{Cu}_{2} \mathrm{O}$ wrapped by graphene & $\mathrm{H}_{2} \mathrm{O}_{2}$ & - & $20.8 \mu \mathrm{M}$ & $0.3-7.8 \mathrm{mM}$ & 233 \\
\hline GO/antibody-AuNRs & Transferrin & - & - & $0.0375-40 \mu \mathrm{g} \mathrm{mL}^{-1}$ & 234 \\
\hline G-chitosan/Fc-S/AuNPs & Rutin & - & $10 \mathrm{nM}$ & $0.04-100 \mu \mathrm{M}$ & 235 \\
\hline $\mathrm{GS} / \mathrm{Fe}_{3} \mathrm{O}_{4} @ \mathrm{Au}-\mathrm{S}-\mathrm{Fc}$ & AA & - & $1 \mu \mathrm{M}$ & $4-400 \mu \mathrm{M}$ & 222 \\
\hline Graphene/AuNPs/PANI & DNA & - & $2.11 \mathrm{pM}$ & $10-1000 \mathrm{pM}$ & 64 \\
\hline Graphene-thionine/Ag@ $\mathrm{Fe}_{3} \mathrm{O}_{4}$ NPs & Kanamycin & - & $15 \mathrm{pg} \mathrm{mL}^{-1}$ & $0.05-16 \mathrm{ng} \mathrm{mL}^{-1}$ & 238 \\
\hline Cells on rGO/AuNPs & $\begin{array}{l}\text { Pheochromocytoma } \\
\text { cell (PC-12) }\end{array}$ & - & $5.2 \times 10^{3}$ cells per $\mathrm{mL}$ & $\begin{array}{l}1.6 \times 10^{4} \text { to } \\
1.6 \times 10^{7} \text { cells per mL }\end{array}$ & 60 \\
\hline $\mathrm{TiO}_{2} /$ graphene/Pt-Pd/AuNPs & Cholesterol & - & $0.017 \mu \mathrm{M}$ & $0.05-590 \mu \mathrm{M}$ & 239 \\
\hline Graphene/PtNi NPs & Glucose & 20.42 & - & Up to $35 \mathrm{mM}$ & 66 \\
\hline $\mathrm{rGO} / \mathrm{Pt}$ & Oxalic acid & - & $10 \mu \mathrm{M}$ & $0.1-15 \mathrm{mM}$ & 216 \\
\hline AuNPs/GO/ITO & Dopamine & 62.7 & $0.06 \mu \mathrm{M}$ & - & 61 \\
\hline Single layer GO/AuNPs & DNA & - & $100 \mathrm{fM}$ & - & 62 \\
\hline
\end{tabular}

Recently, a novel hybrid of mesoporous silica nanoparticles (MSNPs) wrapped with GO was developed as an efficient dyeprotecting vessel, which was applied to protect different types of fluorescent dye. ${ }^{89} \mathrm{Bis}(2,4,6$-trihydroxyphenyl) squaraine dye, a type of zwitterionic molecule, was used as a cargo model. Strong ionic interaction between the negatively charged surface of GO and the positively charged surface of MSNPs plays a key role in hybrid formation (Fig. 13). After MSNPs were wrapped with the GO sheets, the GO-MSNPs obtained exhibited remarkable stability. The loaded squaraine dye in GO-MSNPs was fully protected from attacks by nucleophiles such as cysteine and glutathione. The photophysical properties of the dye loaded GOMSNP hybrid were investigated in aqueous solution at $\mathrm{pH}$ 6.5 with an excitation wavelength of $580 \mathrm{~nm}$. The results showed noninterfering emission bands of the loaded dye, confirming the effective sealing of GO on MSNPs. In vitro fluorescence imaging was carried out using HeLa cells treated with dye loaded GO-MSNPs. The fluorescence images obtained exhibited a clear accumulation of the hybrids in the cell cytoplasm demonstrating a great potential of the vessel for bioimaging applications.

Applications in photothermal and photodynamic therapy were reported using various nanomaterials that possess large 


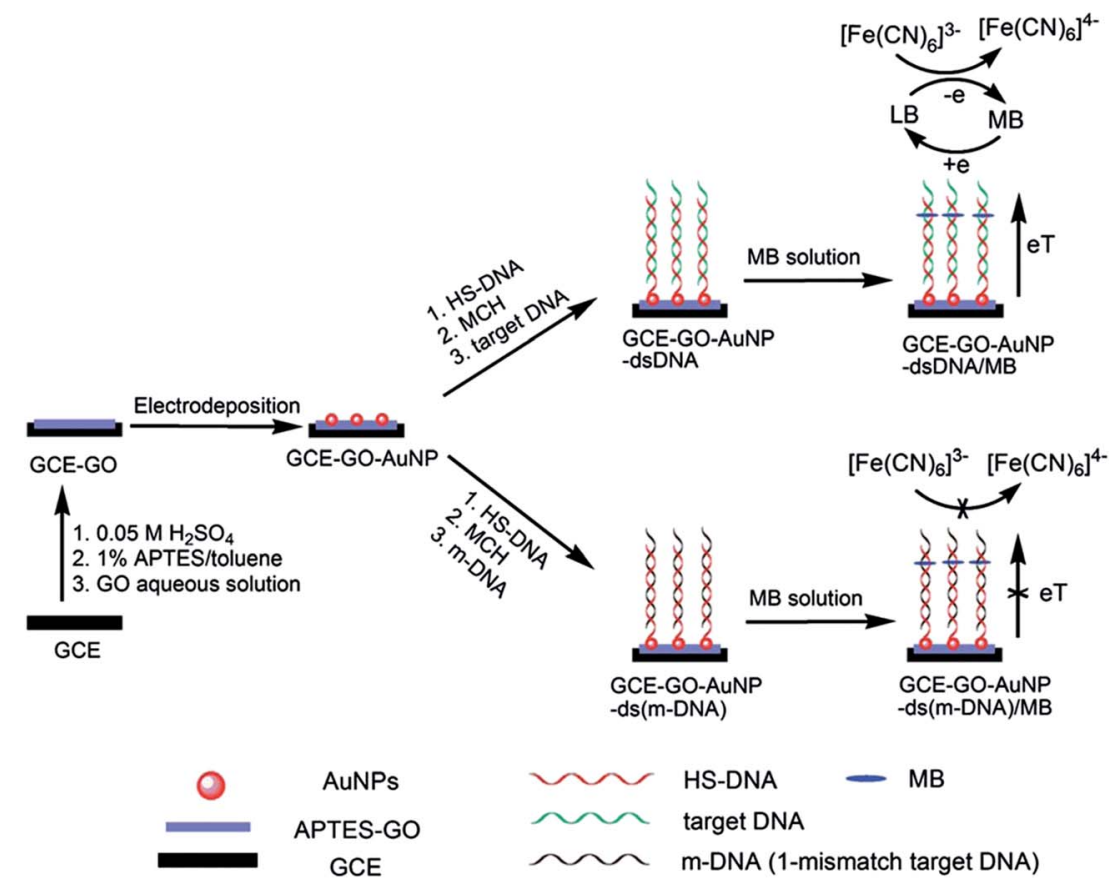

Fig. 11 Schematic representation of the fabrication of a GO/AuNP hybrid-based electrode and its application in DNA detection. Reprinted with permission from ref. 62. Copyright 2012 The Royal Society of Chemistry.

absorption coefficients in the near infrared (NIR) region, such as gold nanorods, ${ }^{241}$ gold nanocubes, ${ }^{242}$ AuNPs, ${ }^{243}$ carbon nanotubes, ${ }^{244}$ quantum dots, ${ }^{245}$ and upconversion nanoparticles (UCNPs). ${ }^{246,247}$ In a fundamental study, the rGO/AuNP hybrid was proven to effectively increase the photothermal energy conversion in comparison to its respective single components. The coupling of surface plasmon resonance (SPR) of AuNPs with laser reduction of $\mathrm{GO}$ was the main factor to dramatically enhance the photothermal effect. By controlling the size and shape of AuNPs, the photothermal efficiency of the final hybrid could be greatly enhanced. ${ }^{248}$ Similarly, the integration of UCNPs with $\mathrm{GO}$ produced promising hybrids. $\mathrm{NaYF}_{4}: \mathrm{Y}-$ $\mathrm{b}^{3+}, \mathrm{Er}^{3+}, \mathrm{Tm}^{3+} / \mathrm{NaYF}_{4}$ UCNPs decorated on PEGylated GO sheets were reported to be an effective NIR imaging agent, and at the same time, to exhibit photodynamic and photothermal therapeutic properties with enhanced anticancer efficacy. ${ }^{249}$ The luminescence imaging and phototherapy of UCNPs were studied in vitro and in vivo. In vitro cancer therapy was
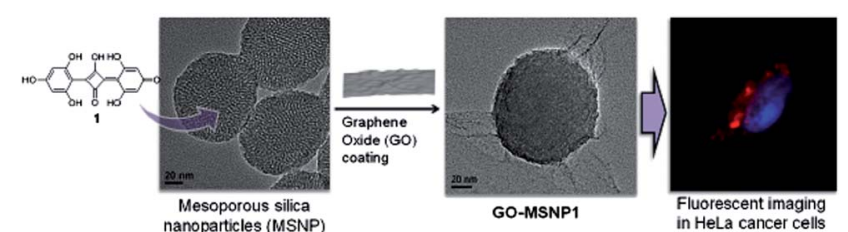

Fig. 13 Schematic representation showing the loading of squaraine dye inside MSNPs followed by wrapping with ultrathin GO sheets, leading to the formation of a novel fluorescent hybrid for cellular imaging. Reprinted with permission from ref. 89. Copyright 2012 American Chemical Society.

demonstrated using HeLa cells, which showed a high therapeutic efficacy. In another recent work, an in vivo dual model of bioimaging and photothermal tumor destruction was demonstrated using iron oxide/AuNP co-decorated GO (GO-IONP-Au-PEG). ${ }^{250}$ The results from this study validated the hypothesis that the more components loaded on the
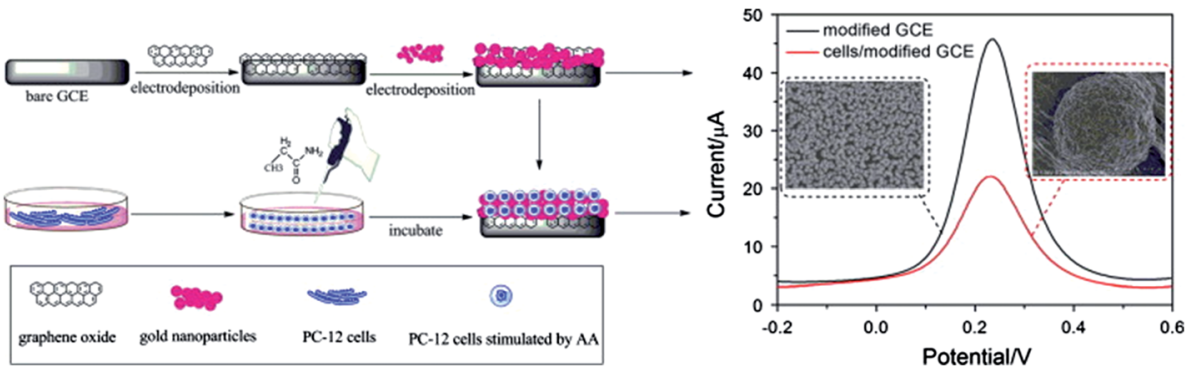

Fig. 12 Schematic representation of the preparation of a cell-based electrochemical sensor. Reproduced with permission from ref. 60 . Copyright 2013 Elsevier. 
graphene sheets, the more synergy properties the hybrid gained (Fig. 14).

In other detailed studies for developing new magnetic resonance imaging (MRI) contrast agents, a simple hybrid of superparamagnetic nanoparticles with graphene sheets was studied thoroughly for its ability to enhance MRI contrast. Superparamagnetic $\mathrm{Fe}_{3} \mathrm{O}_{4}$ nanoparticles have been widely used in biomedical fields as the MRI contrast agent, and the aggregated formation of such nanoparticles has shown an enhancement in relaxation rate $\left(r_{2}\right)$ with better performance. ${ }^{251-254} \mathrm{~A}$ hybrid $\left(\mathrm{Fe}_{3} \mathrm{O}_{4}-\mathrm{GO}\right)$ of $\mathrm{GO}$ with aminodextran-coated $\mathrm{Fe}_{3} \mathrm{O}_{4}$ nanoparticles showed an increase in $T_{2}$ relaxivity $\left(r_{2}=76 \mathrm{Fe}\right.$ $\mathrm{mM}^{-1} \mathrm{~s}^{-1}$ ), which was much higher than that of monodispersed $\mathrm{Fe}_{3} \mathrm{O}_{4}$ nanoparticles $\left(r_{2}=21 \mathrm{Fe} \mathrm{mM}^{-1} \mathrm{~s}^{-1}\right) .{ }^{255}$ In this context, GO served as a platform for $\mathrm{Fe}_{3} \mathrm{O}_{4}$ nanoparticles to assemble and form aggregates, which increased the MRI sensitivity of the hybrid. The hybrid also exhibited good physiological stability and low cytotoxicity as measured by the WST assay. $\mathrm{Fe}_{3} \mathrm{O}_{4}-\mathrm{GO}$ hybrids with different iron concentrations of 10, 20, 40 and $80 \mathrm{~g}$ $\mathrm{mL}^{-1}$ were reported to show 100, 96, 92 and $91 \%$ cell viability, respectively, indicating their biocompatible properties. ${ }^{255}$ In a similar approach, superparamagnetic $\mathrm{MnFe}_{2} \mathrm{O}_{4}$ nanocrystals were anchored onto oleyamine-modified GO, yielding a hybrid with $r_{2}$ relaxivity value as high as $256.2 \mathrm{Fe} \mathrm{mM}^{-1} \mathrm{~s}^{-1} \cdot{ }^{256}$ Coating the $\mathrm{MnFe}_{2} \mathrm{O}_{4}-\mathrm{GO}$ hybrid with long chain polyethylene glycol (MGONCs-4-PEG) improved the colloidal stability and reduced the cytotoxicity in vitro. MGONCs-4-PEG showed a negligible change in hydrodynamic size even after 4 days of incubation in PBS $1 \times$ solution at $25{ }^{\circ} \mathrm{C}$ and $37^{\circ} \mathrm{C}^{256}$

In another study, in situ growth of $\beta$-FeOOH nanorods on PEGylated GO sheets produced a nanohybrid with ultra-high transverse $r_{2}$ relaxivity of $303.81 \mathrm{Fe} \mathrm{mM}^{-1} \mathrm{~s}^{-1}$, which is 60 times higher than those values hitherto reported for $\beta$-FeOOH-based MRI contrast agents. ${ }^{257}$ The GO-PEG- $\beta$-FeOOH hybrid also showed a loading capability of $1.35 \mathrm{mg} \mathrm{mg}^{-1}$ for doxorubicin hydrochloride at $\mathrm{pH}$ 7.4. When the $\mathrm{pH}$ value of the buffer a
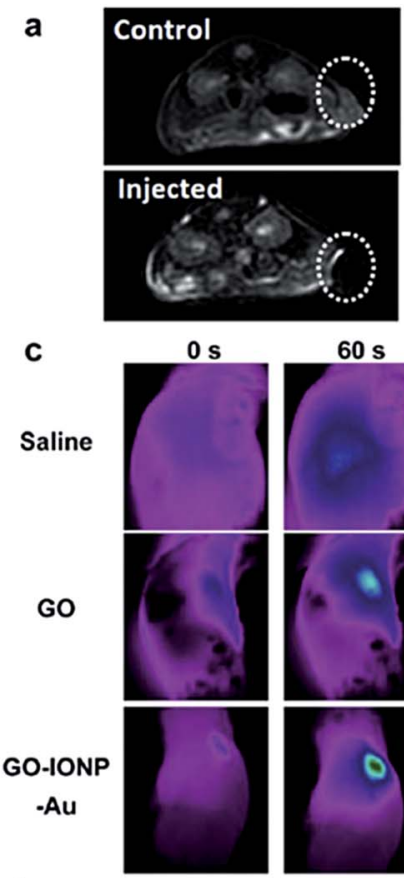

d

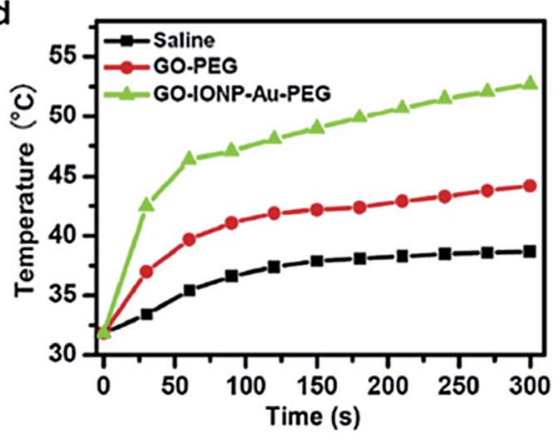

b

$60 \mathrm{~s}$

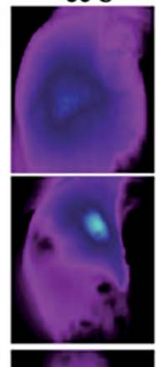

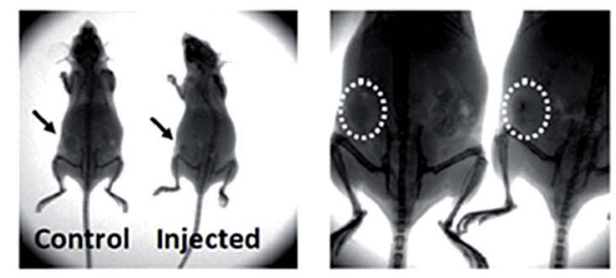
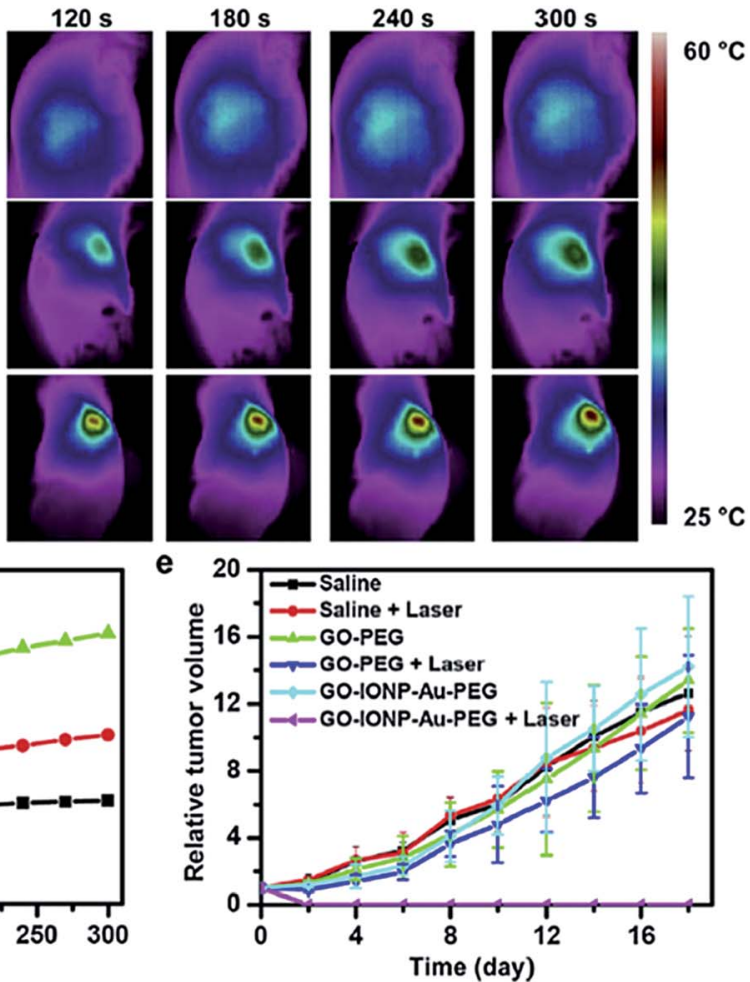

Fig. 14 (a) $T_{2}$-weighted MR images of 4T1 tumor-bearing mice before (top) and after (bottom) intratumoral injection of GO-IONP-Au-PEG. (b) $X$-ray images of tumor-bearing mice before (left) and after (right) intratumoral injection of the hybrid. (c) IR thermal images of tumor-bearing mice injected with corresponding solutions under laser irradiation $\left(808 \mathrm{~nm}, 0.75 \mathrm{~W} \mathrm{~cm}^{-2}\right)$. (d) The temperature changes on tumors of mice under different treatments. (e) The tumor growth curves under the different treatments indicated. Reproduced with permission from ref. 250 . Copyright 2013 Elsevier. 
medium was adjusted to 5.5 , i.e. the normal $\mathrm{pH}$ in an endosome/lysosome environment, around $57 \%$ of DOX loaded on GO-PEG- $\beta$-FeOOH was released. ${ }^{257}$ Furthermore, the obtained hybrid not only performed as an excellent MRI contrast agent on HeLa cells in vitro, but also demonstrated its practical usage in vivo (Fig. 15). Likewise, chitosan functionalized magnetic graphene hybrid was used as a platform for simultaneous gene/ drug delivery to tumor. ${ }^{258}$ Plasmid DNA encoding green fluorescent protein (GFP) and DOX were successfully loaded onto the GO sheet of the hybrid through $\pi-\pi$ stacking interaction, and were efficiently delivered into A549 lung cancer cells and $\mathrm{C} 42 \mathrm{~b}$ prostate cancer cells. In vivo investigations with tumor bearing mice showed both GFP expression and DOX accumulation at the tumor sites at 24 and $48 \mathrm{~h}$ after administration. The bio-nanomaterial presents integrated functions of chemo- and gene-therapeutics as well as real-time diagnostics with the MRI technique.

Wrapping several nanoparticles within the graphene sheets by aerosol-phase synthesis has created a new definition - nanosack, which can be easily loaded with different and multiple components (Fig. 5). The technique has demonstrated efficient wrapping of various types of nanoparticles, such as AuNPs, SiNPs, and $\mathrm{Fe}_{3} \mathrm{O}_{4}$ NPs, as well as different components, such as $\mathrm{Au}-\mathrm{Fe}_{3} \mathrm{O}_{4}$ and $\mathrm{BaTiO}_{3}-$ $\mathrm{Fe}_{3} \mathrm{O}_{4}$ by the graphene sheets. ${ }^{90}$ Multifunctional capability was demonstrated by fabricating dual-purpose magnetically responsive contrast agents for widely used techniques in clinical diagnostics including $\mathrm{MRI}$ and X-ray computed tomography (CT). The suspension of the $\mathrm{rGO} / \mathrm{Au} / \mathrm{Fe}_{3} \mathrm{O}_{4}$ nanosack in carboxymethylcellulose (CMC) gel was used in MRI and CT in comparison with the $\mathrm{rGO} / \mathrm{Fe}_{3} \mathrm{O}_{4}$ and $\mathrm{rGO} /$ AuNP hybrids. The testing sample showed a reduced $r_{2}$ relaxivity of $114.0 \mathrm{~s}^{-1}\left(\mathrm{mg} \mathrm{mL}^{-1}\right)^{-1}$ relative to the $\mathrm{rGO} / \mathrm{Fe}_{3} \mathrm{O}_{4}$ hybrid, and a mean CT number of 25.6 at a concentration of $2000 \mu \mathrm{g} \mathrm{mL}^{-1}$ at $80 \mathrm{kVp}$ of X-ray tube voltage bias, whereas a CT number of 57.8 was recorded for the $\mathrm{rGO} / \mathrm{AuNP}$ hybrid (Fig. 16). The imaging results demonstrate the practicability of using the aforementioned nanosack for dual-modal
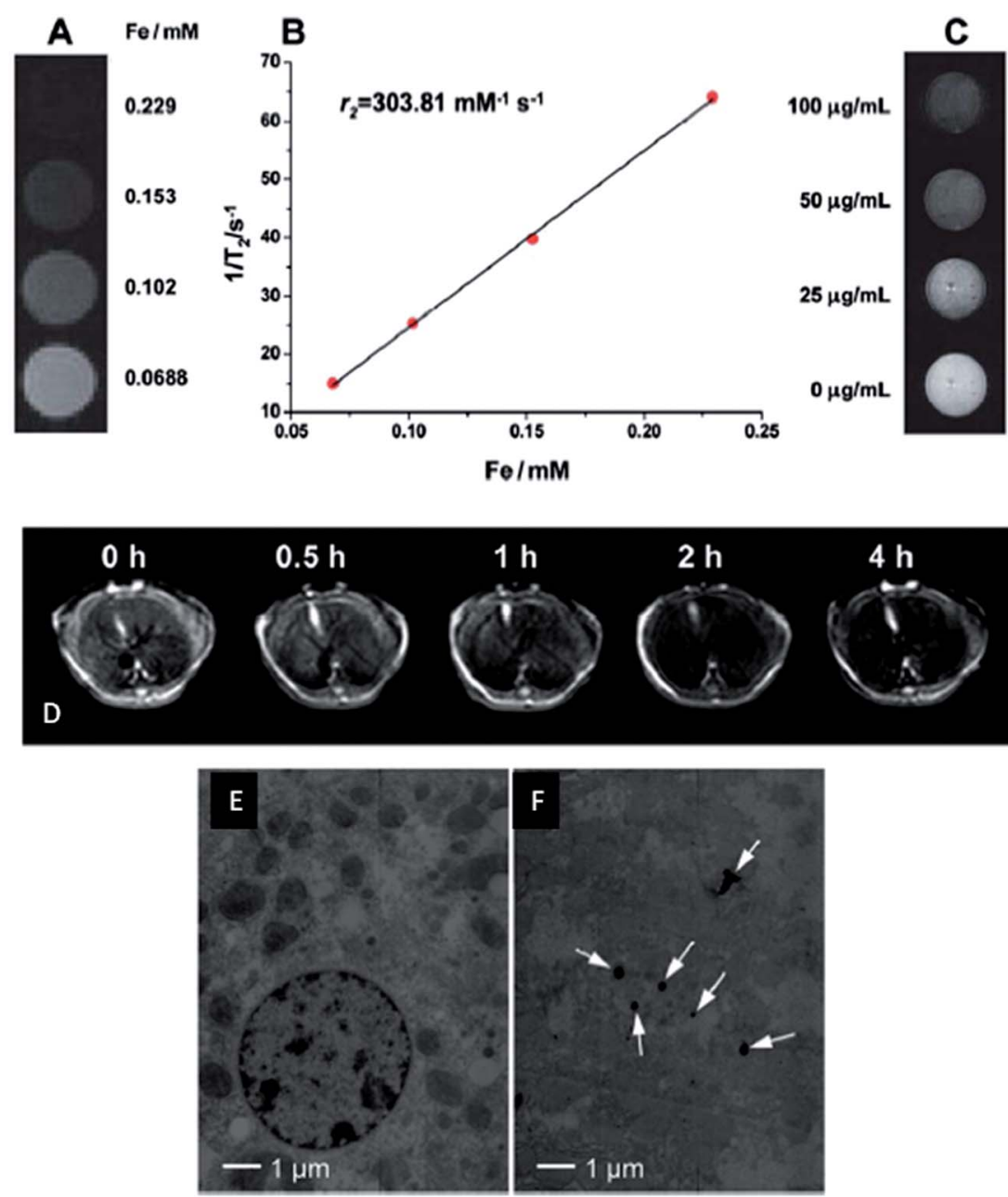

Fig. 15 (A) $T_{2}$-weighted MR images of GO-PEG- $\beta$-FeOOH. (B) Plot of $1 / T_{2}$ versus Fe concentration in GO-PEG- $\beta$-FeOOH, and the slope indicates the specific relaxivity $\left(r_{2}\right)$. (C) $T_{2}$-weighted MR images of HeLa cells after $4 \mathrm{~h}$ incubation with different concentrations of GO-PEG- $\beta$ $\mathrm{FeOOH}$. (D) In vivo $T_{2}$-weighted $\mathrm{MR}$ images of liver before and after intravenous administration of GO-PEG- $\beta$-FeOOH corresponding to 1.0 mg Fe per kg body weight of mice $(0.5,1,2$ and $4 \mathrm{~h}$ post-treatment). TEM images of liver cells (E) before and (F) after intravenous injection of the hybrid. Reproduced with permission from ref. 257. Copyright 2013 The Royal Society of Chemistry. 
imaging of MRI and CT. Moreover, the wrapping architecture of the nanosack enables the hybrid to load and release cargos in a controlled manner. The $\mathrm{rGO} / \mathrm{CsCl} / \mathrm{CMC}$ nanosack showed the ability to release loaded salt over a period of days in comparison to the rapid release of $\mathrm{CsCl}$ (the maximum release was obtained within minutes) when using a $\mathrm{GO} / \mathrm{CsCl}$ hybrid without the CMC sealing additive. This controlled release property of the nanosack combined with the ability of multi-modal imaging for non-invasive MRI and CT open up a new pathway for versatile applications.

Above all, the excellent properties of the graphene/nanoparticle hybrids discussed, the size of graphene and the toxicity of metal/metal oxide nanoparticles still remain a challenge for their practical application in vivo. The size of graphene determines the overall size of the hybrids, which is one of the main factors controlling the enhanced permeability and retention (EPR) effect. Oversize graphene might be partially reduced by centrifugation or vacuum membrane filtration. ${ }^{259}$ On the other hand, although serious toxicity of the nanoparticles employed has rarely been reported, the chronic effect of those nanoparticles is still an important aspect to address in future studies.
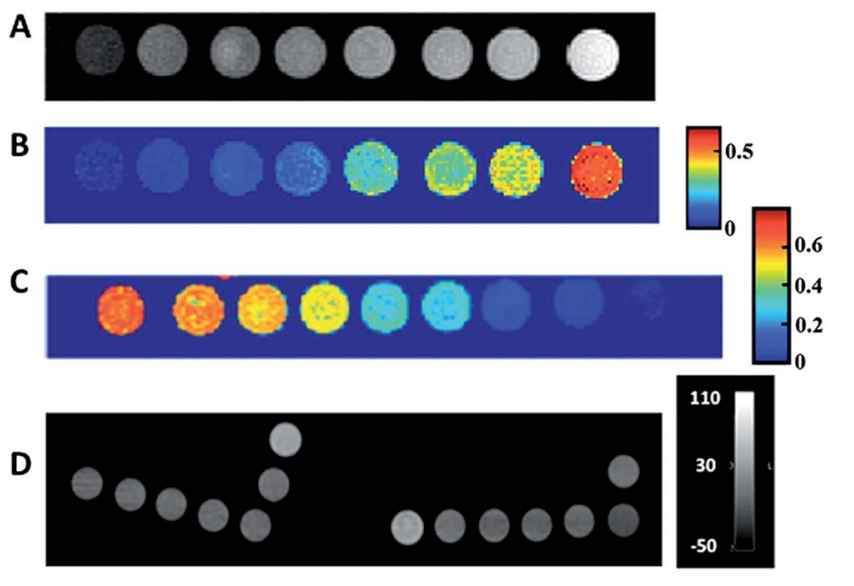

E CT number for $\mathrm{G} / \mathrm{Au}$ and $\mathrm{G} / \mathrm{Au} / \mathrm{Fe}_{3} \mathrm{O}_{4}$ multimodal nanosacks

\begin{tabular}{|l|l|l|l|l|}
\hline Sample & $80 \mathrm{kVp}$ & $100 \mathrm{kV}$ & $120 \mathrm{kVp}$ & $140 \mathrm{kVp}$ \\
\hline $\mathrm{G} / \mathrm{Au}$ & $57.78(1.061)$ & $47.01(1.049)$ & $53.27(1.056)$ & $49.34(1.051)$ \\
\hline $\mathrm{G} / \mathrm{Au} / \mathrm{Fe}_{3} \mathrm{O}_{4}$ & $25.61(1.045)$ & $22.26(1.032)$ & $23.65(1.041)$ & $16.67(1.035)$ \\
\hline
\end{tabular}

Fig. 16 Clinical MRI and X-ray CT results of $\mathrm{rGO} / \mathrm{Fe}_{3} \mathrm{O}_{4}, \mathrm{rGO} / \mathrm{AuNPs}$ and $\mathrm{rGO} / \mathrm{Au} / \mathrm{Fe}_{3} \mathrm{O}_{4}$ multifunctional probes. (A) $T_{2}$-weighted image of $\mathrm{rGO} / \mathrm{Fe}_{3} \mathrm{O}_{4}$ with the concentration increase from right to left: $0,0.5,1$, $2,5,10,20$, and $50 \mu \mathrm{g} \mathrm{mL}^{-1}$. (B) $T_{2}$ map computed from 24 echo image series. Color bar is $T_{2}$ in seconds. (C) $M R I T_{2}$ map of $\mathrm{rGO} / \mathrm{Au} / \mathrm{Fe}_{3} \mathrm{O}_{4}$ with the concentration increase from left to right: $0.05,0.1,0.5,1,5,10,50$, 100 , and $500 \mu \mathrm{g} \mathrm{mL}^{-1}$. (D) X-ray CT image ( $80 \mathrm{kVp}$ ) of graphene/Au nanosack. Right-hand $L$-shaped sequence for the nanosack with concentrations in $\mu \mathrm{g} \mathrm{mL}^{-1}$ from left to right: $2000,400,200,40,20$, gel control, and water control. Left-hand $L$-shaped sequence for free Au control with concentrations in $\mu \mathrm{g} \mathrm{mL}^{-1}$ from left to right: 400,200 , 40,20 , gel control with $2000 \mu \mathrm{g} \mathrm{mL}^{-1}$ of empty nanosack at top, and with $200 \mu \mathrm{g} \mathrm{mL}^{-1}$ of empty nanosack beneath it. (E) Table of CT results showing the changes in CT number relative to the gel control samples shown in parentheses. Reprinted with permission from ref. 90. Copyright 2013 American Chemical Society.

\section{Conclusions and future prospect of graphene/nanoparticle hybrids}

Recent achievements of different types of graphene/nanoparticle hybrid have been discussed in this review. Many graphene/nanoparticle hybrids have been reported in the literature owing to the abundant ways of combining nanoparticles and graphene (and its derivatives). On the one hand, nanoparticles with specific properties can be obtained by tuning their size, shape, and surface functionality. Changing the intrinsic features from metal, metal oxide, and semiconductor nanoparticles to mesoporous nanoparticles introduces entirely different properties to the final hybrids. On the other hand, graphene and its derivatives provide excellent platforms for various modifications.

Synthetic methods for decorating nanoparticles onto graphene and its derivatives as well as wrapping nanoparticles by graphene and its graphene derivatives have been summarized and compared for their possibilities in large-scale production. Although conventional CVD graphene with nanoparticles shows distinctive performance in electronics applications, non-solution phase synthesis is not possible in mass production due to the high costs involved and low synthetic efficiency. Solution phase fabrication has gained more attention on account of its facile and low-cost production. Different hybrids synthesized by the solution method using the rGO and GO platforms have been discussed, and their potential applications have been highlighted. In the field of TCFs, hybrids with comparable conductivity and transparency to ITO have been developed. Together with good flexibility and low processing costs, these new hybrids are promising materials to replace conventional ITO in TCF production.

Application of the graphene/nanoparticle hybrids in energy harvesting is another major research area. The ability to convert light energy to electricity using graphene/quantum dot hybrids has been discussed in detail, where different types of quantum dots absorb photons within a wide light spectrum from UV through to infrared region. These results have paved the way for developing novel graphene/nanoparticle hybrids for broad range spectrum detection. Efficient and cost-effective production of hybrids is also anticipated in solar cell applications.

In the field of energy storage, the introduction of graphene/ nanoparticle hybrids could enhance the capacity as well as the stability of metal-based electrodes. Various impact factors from using graphene have been highlighted. Interestingly, by tuning the morphology of nanoparticles from spherical shape to a sheet-like structure, higher capacity and higher retention rates have been obtained. This opens up a new pathway for further improving the performance of energy storage materials. Rational combinations of nanoparticles and graphene derivatives are expected to raise the capacity and stability to another level.

Biological applications of graphene/nanoparticle hybrids are significantly influencing current biotechnology. The hybrids enable the development of electrochemical biosensors with enhanced sensitivity, better selectivity, a wide range of detection, and ease of fabrication. Multi-component detection has 
also been achieved with a low detection limit and a high sensitivity. The biocompatible properties of the hybrids make them applicable for in situ detection of living cells. Rapid, accurate, multi-purpose and low-cost biosensors based on graphene/nanoparticle hybrids are expected to be in mass production in the near future.

Graphene/nanoparticle hybrids have undoubtedly presented marvelous potential in the field of imaging, treatment and drug delivery. Some representative hybrids along with their outstanding performance in different aspects of this field have been highlighted in this review. Hybrids for non-invasive bioimaging, photodynamic therapy, and co-delivery of drug and genes have been showcased. Current research developments have shown a promising outlook for the application of graphene/nanoparticle hybrids in real-life diagnostics and therapeutics. Since the biocompatibility and toxicity of such hybrids in biological systems have not been well addressed, in-depth investigations need to be carried out before their real-life applications can be considered.

\section{Acknowledgements}

This work was financially supported by the Singapore National Research Foundation Fellowship (NRF2009NRFRF001-015), the Singapore National Research Foundation CREATE programSingapore Peking University Research Centre for a Sustainable Low-Carbon Future, and the NTU-A*Star Centre of Excellence for Silicon Technologies (A*Star SERC no. 112351 0003).

\section{Notes and references}

1 A. K. Geim, Science, 2009, 324, 1530-1534.

2 C. Lee, X. Wei, J. W. Kysar and J. Hone, Science, 2008, 321, 385-388.

3 M. D. Stoller, S. Park, Z. Yanwu, J. An and R. S. Ruoff, Nano Lett., 2008, 8, 3498-3502.

4 A. A. Balandin, S. Ghosh, W. Bao, I. Calizo, D. Teweldebrhan, F. Miao and C. N. Lau, Nano Lett., 2008, 8, 902-907.

5 S. Ghosh, W. Bao, D. L. Nika, S. Subrina, E. P. Pokatilov, C. N. Lau and A. A. Balandin, Nat. Mater., 2010, 9, 555-558.

6 R. R. Nair, P. Blake, A. N. Grigorenko, K. S. Novoselov, T. J. Booth, T. Stauber, N. M. R. Peres and A. K. Geim, Science, 2008, 320, 1308.

7 S. Bae, H. Kim, Y. Lee, X. Xu, J. S. Park, Y. Zheng, J. Balakrishnan, T. Lei, H. Ri Kim, Y. I. Song, Y. J. Kim, K. S. Kim, B. Özyilmaz, J. H. Ahn, B. H. Hong and S. Iijima, Nat. Nanotechnol., 2010, 5, 574-578.

8 K. S. Kim, Y. Zhao, H. Jang, S. Y. Lee, J. M. Kim, K. S. Kim, J.-H. Ahn, P. Kim, J.-Y. Choi and B. H. Hong, Nature, 2009, 457, 706-710.

9 X. Li, Y. Zhu, W. Cai, M. Borysiak, B. Han, D. Chen, R. D. Piner, L. Colombo and R. S. Ruoff, Nano Lett., 2009, 9, 4359-4363.

10 K. S. Novoselov, D. Jiang, F. Schedin, T. J. Booth, V. V. Khotkevich, S. V. Morozov and A. K. Geim, Proc. Natl. Acad. Sci. U. S. A., 2005, 102, 10451-10453.
11 K. S. Novoselov, A. K. Geim, S. V. Morozov, D. Jiang, M. I. Katsnelson, I. V. Grigorieva, S. V. Dubonos and A. A. Firsov, Nature, 2005, 438, 197-200.

12 Y. Zhang, Y.-W. Tan, H. L. Stormer and P. Kim, Nature, 2005, 438, 201-204.

13 A. K. Geim and K. S. Novoselov, Nat. Mater., 2007, 6, 183191.

14 S. V. Morozov, K. S. Novoselov, M. I. Katsnelson, F. Schedin, D. C. Elias, J. A. Jaszczak and A. K. Geim, Phys. Rev. Lett., 2008, 100, 016602.

15 Y. M. Lin, C. Dimitrakopoulos, K. A. Jenkins, D. B. Farmer, H. Y. Chiu, A. Grill and P. Avouris, Science, 2010, 327, 662 .

16 F. Schedin, A. K. Geim, S. V. Morozov, E. W. Hill, P. Blake, M. I. Katsnelson and K. S. Novoselov, Nat. Mater., 2007, 6, 652-655.

17 L. Liao, J. Bai, Y. C. Lin, Y. Qu, Y. Huang and X. Duan, $A d v$. Mater., 2010, 22, 1941-1945.

18 N. O. Weiss, H. Zhou, L. Liao, Y. Liu, S. Jiang, Y. Huang and X. Duan, Adv. Mater., 2012, 24, 5782-5825.

19 P. R. Wallace, Phys. Rev., 1947, 71, 622-634.

20 K. S. Novoselov, A. K. Geim, S. V. Morozov, D. Jiang, Y. Zhang, S. V. Dubonos, I. V. Grigorieva and A. A. Firsov, Science, 2004, 306, 666-669.

21 D. R. Dreyer, S. Park, C. W. Bielawski and R. S. Ruoff, Chem. Soc. Rev., 2010, 39, 228-240.

22 X. Huang, X. Qi, F. Boey and H. Zhang, Chem. Soc. Rev., 2012, 41, 666-686.

23 G. Eda and M. Chhowalla, Adv. Mater., 2010, 22, 2392-2415.

24 S. Pei and H. M. Cheng, Carbon, 2012, 50, 3210-3228.

25 D. A. Dikin, S. Stankovich, E. J. Zimney, R. D. Piner, G. H. B. Dommett, G. Evmenenko, S. T. Nguyen and R. S. Ruoff, Nature, 2007, 448, 457-460.

26 J. T. Robinson, F. K. Perkins, E. S. Snow, Z. Wei and P. E. Sheehan, Nano Lett., 2008, 8, 3137-3140.

27 H. Yan, L. Zhu, X. Li, A. Kwok, X. Pan and Y. Zhao, Asian J. Org. Chem., 2012, 1, 314-318.

28 X. Pan, H. Li, K. T. Nguyen, G. Grüner and Y. Zhao, J. Phys. Chem. C, 2012, 116, 4175-4181.

29 V. C. Sanchez, A. Jachak, R. H. Hurt and A. B. Kane, Chem. Res. Toxicol., 2012, 25, 15-34.

30 H. Zhang, G. Grüner and Y. Zhao, J. Mater. Chem. B, 2013, 1, 2542-2567.

$31 \mathrm{H}$. Varela-Rizo, I. Martín-Gullón and M. Terrones, ACS Nano, 2012, 6, 4565-4572.

32 H. Zhou, C. Qiu, Z. Liu, H. Yang, L. Hu, J. Liu, C. Gu and L. Sun, J. Am. Chem. Soc., 2010, 132, 944-946.

33 R. Bajpai, S. Roy, P. Kumar, P. Bajpai, N. Kulshrestha, J. Rafiee, N. Koratkar and D. S. Misra, ACS Appl. Mater. Interfaces, 2011, 3, 3884-3889.

34 R. Bajpai, S. Roy, N. Kulshrestha, J. Rafiee, N. Koratkar and D. S. Misra, Nanoscale, 2012, 4, 926-930.

35 J. Y. Son, Y.-H. Shin, H. Kim and H. M. Jang, ACS Nano, 2010, 4, 2655-2658.

36 Q. Liu, L. Wei, J. Wang, F. Peng, D. Luo, R. Cui, Y. Niu, X. Qin, Y. Liu, H. Sun, J. Yang and Y. Li, Nanoscale, 2012, 4, 7084-7089. 
37 G. Goncalves, P. A. A. P. Marques, C. M. Granadeiro, H. I. S. Nogueira, M. K. Singh and J. Grácio, Chem. Mater., 2009, 21, 4796-4802.

38 C. Shi, J. Meng and C. Deng, Chem. Commun., 2012, 48, 2418-2420.

39 T. Cassagneau and J. H. Fendler, J. Phys. Chem. B, 1999, 103, 1789-1793.

40 R. Muszynski, B. Seger and P. V. Kamat, J. Phys. Chem. C, 2008, 112, 5263-5266.

41 S. Guo, S. Dong and E. Wang, ACS Nano, 2009, 4, 547-555.

42 Y. G. Kim, Z. A. Akbar, D. Y. Kim, S. M. Jo and S. Y. Jang, ACS Appl. Mater. Interfaces, 2013, 5, 2053-2061.

43 X. Fu, F. Bei, X. Wang, S. O'Brien and J. R. Lombardi, Nanoscale, 2010, 2, 1461-1466.

44 Y. Lin, K. Zhang, W. Chen, Y. Liu, Z. Geng, J. Zeng, N. Pan, L. Yan, X. Wang and J. G. Hou, ACS Nano, 2010, 4, 30333038.

45 D. Marquardt, C. Vollmer, R. Thomann, P. Steurer, R. Mülhaupt, E. Redel and C. Janiak, Carbon, 2011, 49, 1326-1332.

46 J. Yan, T. Wei, W. Qiao, B. Shao, Q. Zhao, L. Zhang and Z. Fan, Electrochim. Acta, 2010, 55, 6973-6978.

47 J. Yan, Z. Fan, T. Wei, W. Qian, M. Zhang and F. Wei, Carbon, 2010, 48, 3825-3833.

48 H. M. A. Hassan, V. Abdelsayed, A. E. R. S. Khder, K. M. AbouZeid, J. Terner, M. S. El-Shall, S. I. Al-Resayes and A. A. El-Azhary, J. Mater. Chem., 2009, 19, 3832-3837.

49 K. Jasuja, J. Linn, S. Melton and V. Berry, J. Phys. Chem. Lett., 2010, 1, 1853-1860.

50 J. Su, M. Cao, L. Ren and C. Hu, J. Phys. Chem. C, 2011, 115, 14469-14477.

51 Y. Li, G. Wang, K. Pan, B. Jiang, C. Tian, W. Zhou and H. Fu, J. Mater. Chem., 2012, 22, 20381-20386.

52 M. Du, C. Xu, J. Sun and L. Gao, J. Mater. Chem. A, 2013, 1, 7154-7158.

53 W. Fan, Q. Lai, Q. Zhang and Y. Wang, J. Phys. Chem. C, 2011, 115, 10694-10701.

54 M. Long, Y. Qin, C. Chen, X. Guo, B. Tan and W. Cai, J. Phys. Chem. C, 2013, 117, 16734-16741.

55 J. Shen, B. Yan, M. Shi, H. Ma, N. Li and M. Ye, J. Mater. Chem., 2011, 21, 3415-3421.

56 M. S. Artiles, C. S. Rout and T. S. Fisher, Adv. Drug Delivery Rev., 2011, 63, 1352-1360.

57 E. Morales-Narváez and A. Merkoçi, Adv. Mater., 2012, 24, 3298-3308.

58 C. Shan, H. Yang, J. Song, D. Han, A. Ivaska and L. Niu, Anal. Chem., 2009, 81, 2378-2382.

59 Z. Zhong, W. Wu, D. Wang, J. Shan, Y. Qing and Z. Zhang, Biosens. Bioelectron., 2010, 25, 2379-2383.

60 X. Sun, J. Ji, D. Jiang, X. Li, Y. Zhang, Z. Li and Y. Wu, Biosens. Bioelectron., 2013, 44, 122-126.

61 J. Yang, J. R. Strickler and S. Gunasekaran, Nanoscale, 2012, 4, 4594-4602.

62 Z. Wang, J. Zhang, Z. Yin, S. Wu, D. Mandler and H. Zhang, Nanoscale, 2012, 4, 2728-2733.

63 J. Yang, S. Deng, J. Lei, H. Ju and S. Gunasekaran, Biosens. Bioelectron., 2011, 29, 159-166.
64 L. Wang, E. Hua, M. Liang, C. Ma, Z. Liu, S. Sheng, M. Liu, G. Xie and W. Feng, Biosens. Bioelectron., 2014, 51, 201-207. 65 Y. Wang, J. Ping, Z. Ye, J. Wu and Y. Ying, Biosens. Bioelectron., 2013, 49, 492-498.

66 H. Gao, F. Xiao, C. B. Ching and H. Duan, ACS Appl. Mater. Interfaces, 2011, 3, 3049-3057.

67 A. Allain, Z. Han and V. Bouchiat, Nat. Mater., 2012, 11, 590594.

68 Y.-T. Kim, J. H. Han, B. H. Hong and Y.-U. Kwon, Adv. Mater., 2010, 22, 515-518.

69 K. Jasuja and V. Berry, ACS Nano, 2009, 3, 2358-2366.

70 B. K. Barman and K. K. Nanda, Chem. Commun., 2013, 49, 8949-8951.

71 Z. Niu, J. Du, X. Cao, Y. Sun, W. Zhou, H. H. Hng, J. Ma, X. Chen and S. Xie, Small, 2012, 8, 3201-3208.

72 C. Burda, X. Chen, R. Narayanan and M. A. El-Sayed, Chem. Rev., 2005, 105, 1025-1102.

73 M. Grzelczak, J. Pérez-Juste, P. Mulvaney and L. M. LizMarzán, Chem. Soc. Rev., 2008, 37, 1783-1791.

74 Y. Xia, Y. Xiong, B. Lim and S. E. Skrabalak, Angew. Chem., Int. Ed., 2009, 48, 60-103.

75 M. Rycenga, C. M. Cobley, J. Zeng, W. Li, C. H. Moran, Q. Zhang, D. Qin and Y. Xia, Chem. Rev., 2011, 111, 36693712.

76 S. Eustis and M. A. El-Sayed, Chem. Soc. Rev., 2006, 35, 209217.

77 A. R. Tao, S. Habas and P. Yang, Small, 2008, 4, 310-325.

78 K. T. Nguyen, D. Li, P. Borah, X. Ma, Z. Liu, L. Zhu, G. Grüner, Q. Xiong and Y. Zhao, ACS Appl. Mater. Interfaces, 2013, 5, 8105-8110.

79 J. Liu, S. Fu, B. Yuan, Y. Li and Z. Deng, J. Am. Chem. Soc., 2010, 132, 7279-7281.

80 S. Yang, X. Feng, S. Ivanovici and K. Müllen, Angew. Chem., Int. Ed., 2010, 49, 8408-8411.

81 Z. Zheng, Y. Cheng, X. Yan, R. Wang and P. Zhang, J. Mater. Chem. A, 2014, 2, 149-154.

82 X. Ma, Q. Qu, Y. Zhao, Z. Luo, Y. Zhao, K. W. Ng and Y. Zhao, J. Mater. Chem. B, 2013, 1, 6495-6500.

83 J. Zhu and J. He, ACS Appl. Mater. Interfaces, 2012, 4, 17701776.

84 J. S. Chen, Z. Wang, X. C. Dong, P. Chen and X. W. Lou, Nanoscale, 2011, 3, 2158-2161.

85 Y.-S. He, P. Gao, J. Chen, X. Yang, X.-Z. Liao, J. Yang and Z.-F. Ma, RSC Adv., 2011, 1, 958-960.

86 D. Deng and J. Y. Lee, Angew. Chem., 2009, 121, 1688-1691. 87 C. K. Chan, H. Peng, G. Liu, K. McIlwrath, X. F. Zhang, R. A. Huggins and Y. Cui, Nat. Nanotechnol., 2008, 3, 31-35. 88 W.-M. Zhang, J.-S. Hu, Y.-G. Guo, S.-F. Zheng, L.-S. Zhong, W.-G. Song and L.-J. Wan, Adv. Mater., 2008, 20, 1160-1165.

89 S. Sreejith, X. Ma and Y. Zhao, J. Am. Chem. Soc., 2012, 134, 17346-17349.

90 Y. Chen, F. Guo, Y. Qiu, H. Hu, I. Kulaots, E. Walsh and R. H. Hurt, ACS Nano, 2013, 7, 3744-3753.

91 Y. Chen, F. Guo, A. Jachak, S.-P. Kim, D. Datta, J. Liu, I. Kulaots, C. Vaslet, H. D. Jang, J. Huang, A. Kane, V. B. Shenoy and R. H. Hurt, Nano Lett., 2012, 12, 19962002. 
92 D. Li and R. B. Kaner, Science, 2008, 320, 1170-1171.

93 D. Jariwala, V. K. Sangwan, L. J. Lauhon, T. J. Marks and M. C. Hersam, Chem. Soc. Rev., 2013, 42, 2824-2860.

94 F. Schwierz, Nat. Nanotechnol., 2010, 5, 487-496.

95 M. Dragoman and D. Dragoman, Prog. Quantum Electron., 2009, 33, 165-214.

96 K. S. Novoselov, V. I. Fal'Ko, L. Colombo, P. R. Gellert, M. G. Schwab and K. Kim, Nature, 2012, 490, 192-200.

97 T. Kuila, S. Bose, P. Khanra, A. K. Mishra, N. H. Kim and J. H. Lee, Biosens. Bioelectron., 2011, 26, 4637-4648.

98 J. K. Wassei and R. B. Kaner, Mater. Today, 2010, 13, 52-59.

99 L. Grande, V. T. Chundi, D. Wei, C. Bower, P. Andrew and T. Ryhänen, Particuology, 2012, 10, 1-8.

100 D. A. C. Brownson, D. K. Kampouris and C. E. Banks, Chem. Soc. Rev., 2012, 41, 6944-6976.

101 L. Yan, Y. B. Zheng, F. Zhao, S. Li, X. Gao, B. Xu, P. S. Weiss and Y. Zhao, Chem. Soc. Rev., 2012, 41, 97-114.

102 M. F. Craciun, S. Russo, M. Yamamoto and S. Tarucha, Nano Today, 2011, 6, 42-60.

103 Q. Cao and J. A. Rogers, Adv. Mater., 2009, 21, 29-53.

104 A. L. Dawar and J. C. Joshi, J. Mater. Sci., 1984, 19, 1-23.

105 G. J. Exarhos and X. D. Zhou, Thin Solid Films, 2007, 515, 7025-7052.

106 I. F. Perepichka, D. F. Perepichka, H. Meng and F. Wudl, Adv. Mater., 2005, 17, 2281-2305.

107 D. Angmo and F. C. Krebs, J. Appl. Polym. Sci., 2013, 129, 114.

108 G. Greczynski, T. Kugler, M. Keil, W. Osikowicz, M. Fahlman and W. R. Salaneck, J. Electron Spectrosc. Relat. Phenom., 2001, 121, 1-17.

109 J. Jang, Adv. Polym. Sci., 2006, 199, 189-259.

110 V. Saxena and B. D. Malhotra, Curr. Appl. Phys., 2003, 3, 293-305.

111 K. Tvingstedt and O. Inganäs, Adv. Mater., 2007, 19, 28932897.

112 M.-G. Kang, M.-S. Kim, J. Kim and L. J. Guo, Adv. Mater., 2008, 20, 4408-4413.

113 W. Gaynor, G. F. Burkhard, M. D. McGehee and P. Peumans, Adv. Mater., 2011, 23, 2905-2910.

114 J.-Y. Lee, S. T. Connor, Y. Cui and P. Peumans, Nano Lett., 2008, 8, 689-692.

115 L. Yang, T. Zhang, H. Zhou, S. C. Price, B. J. Wiley and W. You, ACS Appl. Mater. Interfaces, 2011, 3, 40754084.

116 S. De, T. M. Higgins, P. E. Lyons, E. M. Doherty, P. N. Nirmalraj, W. J. Blau, J. J. Boland and J. N. Coleman, ACS Nano, 2009, 3, 1767-1774.

117 A. R. Madaria, A. Kumar and C. Zhou, Nanotechnology, 2011, 22, 245201.

118 S. De and J. N. Coleman, ACS Nano, 2010, 4, 2713-2720.

119 J. Borghetti, V. Derycke, S. Lenfant, P. Chenevier, A. Filoramo, M. Goffman, D. Vuillaume and J. P. Bourgoin, Adv. Mater., 2006, 18, 2535-2540.

120 B.-S. Kong, D.-H. Jung, S.-K. Oh, C.-S. Han and H.-T. Jung, J. Phys. Chem. C, 2007, 111, 8377-8382.

121 M. D. Lima, M. J. de Andrade, C. P. Bergmann and S. Roth, J. Mater. Chem., 2008, 18, 776-779.
122 J. Kang, S. Hwang, J. H. Kim, M. H. Kim, J. Ryu, S. J. Seo, B. H. Hong, M. K. Kim and J.-B. Choi, ACS Nano, 2012, 6, 5360-5365.

123 H. Park, P. R. Brown, V. Bulović and J. Kong, Nano Lett., 2011, 12, 133-140.

124 M. P. De Jong, L. J. Van Ijzendoorn and M. J. A. De Voigt, Appl. Phys. Lett., 2000, 77, 2255-2257.

125 J. Y. Kim, J. H. Jung, D. E. Lee and J. Joo, Synth. Met., 2002, 126, 311-316.

126 S. Kirchmeyer and K. Reuter, J. Mater. Chem., 2005, 15, 2077-2088.

127 Y. Zhou, H. Cheun, S. Choi, W. J. Potscavage, C. FuentesHernandez and B. Kippelen, Appl. Phys. Lett., 2010, 97, 153304.

128 H.-Z. Geng, K. K. Kim, K. P. So, Y. S. Lee, Y. Chang and Y. H. Lee, J. Am. Chem. Soc., 2007, 129, 7758-7759.

129 D. Li, M. B. Muller, S. Gilje, R. B. Kaner and G. G. Wallace, Nat. Nanotechnol., 2008, 3, 101-105.

130 L. J. Cote, F. Kim and J. Huang, J. Am. Chem. Soc., 2008, 131, 1043-1049.

131 X. Li, G. Zhang, X. Bai, X. Sun, X. Wang, E. Wang and H. Dai, Nat. Nanotechnol., 2008, 3, 538-542.

132 P. Blake, P. D. Brimicombe, R. R. Nair, T. J. Booth, D. Jiang, F. Schedin, L. A. Ponomarenko, S. V. Morozov, H. F. Gleeson, E. W. Hill, A. K. Geim and K. S. Novoselov, Nano Lett., 2008, 8, 1704-1708.

133 J.-H. Chen, C. Jang, S. Xiao, M. Ishigami and M. S. Fuhrer, Nat. Nanotechnol., 2008, 3, 206-209.

134 Y. Kim, W. Song, S. I. Lee, S. Youb Lee, M. J. Cha, D. Sung Jung and C. Y. Park, Appl. Phys. Lett., 2013, 102, 223116.

135 V. D. Dao, L. V. Nang, E. T. Kim, J. K. Lee and H. S. Choi, ChemSusChem, 2013, 6, 1316-1319.

136 Y. Zhou, J. Yang, X. Cheng, N. Zhao, H. Sun and D. Li, RSC Adv., 2013, 3, 3391-3398.

137 Y. A. Li, Y. J. Chen and N. H. Tai, Langmuir, 2013, 29, 84338439.

138 I. N. Kholmanov, M. D. Stoller, J. Edgeworth, W. H. Lee, H. Li, J. Lee, C. Barnhart, J. R. Potts, R. Piner, D. Akinwande, J. E. Barrick and R. S. Ruoff, ACS Nano, 2012, 6, 5157-5163.

139 A. Kumar and C. Zhou, ACS Nano, 2010, 4, 11-14.

140 J. Wu, M. Agrawal, H. A. Becerril, Z. Bao, Z. Liu, Y. Chen and P. Peumans, ACS Nano, 2009, 4, 43-48.

141 P. Brown and P. V. Kamat, J. Am. Chem. Soc., 2008, 130, 8890-8891.

142 B. Farrow and P. V. Kamat, J. Am. Chem. Soc., 2009, 131, 11124-11131.

143 I. Robel, B. A. Bunker and P. V. Kamat, Adv. Mater., 2005, 17, 2458-2463.

144 L. Hu, Y. L. Zhao, K. Ryu, C. Zhou, J. F. Stoddart and G. Grüner, Adv. Mater., 2008, 20, 939-946.

145 Z. Liu, Q. Liu, Y. Huang, Y. Ma, S. Yin, X. Zhang, W. Sun and Y. Chen, Adv. Mater., 2008, 20, 3924-3930.

146 A. Cao, Z. Liu, S. Chu, M. Wu, Z. Ye, Z. Cai, Y. Chang, S. Wang, Q. Gong and Y. Liu, Adv. Mater., 2010, 22, 103-106.

147 Z. Lu, C. X. Guo, H. B. Yang, Y. Qiao, J. Guo and C. M. Li, J. Colloid Interface Sci., 2011, 353, 588-592. 
148 I. V. Lightcap and P. V. Kamat, J. Am. Chem. Soc., 2012, 134, 7109-7116.

149 J. Chen, F. Xu, J. Wu, K. Qasim, Y. Zhou, W. Lei, L. T. Sun and Y. Zhang, Nanoscale, 2012, 4, 441-443.

150 X. Geng, L. Niu, Z. Xing, R. Song, G. Liu, M. Sun, G. Cheng, H. Zhong, Z. Liu, Z. Zhang, L. Sun, H. Xu, L. Lu and L. Liu, Adv. Mater., 2010, 22, 638-642.

151 D. Zhang, L. Gan, Y. Cao, Q. Wang, L. Qi and X. Guo, Adv. Mater., 2012, 24, 2715-2720.

152 Z. Sun, Z. Liu, J. Li, G. A. Tai, S. P. Lau and F. Yan, Adv. Mater., 2012, 24, 5878-5883.

153 K. Zheng, F. Meng, L. Jiang, Q. Yan, H. H. Hng and X. Chen, Small, 2013, 9, 2076-2080.

154 S. Yin, Y. Goldovsky, M. Herzberg, L. Liu, H. Sun, Y. Zhang, F. Meng, X. Cao, D. D. Sun, H. Chen, A. Kushmaro and X. Chen, Adv. Funct. Mater., 2013, 23, 2972-2978.

155 F. Belliard, P. A. Connor and J. T. S. Irvine, Solid State Ionics, 2000, 135, 163-167.

156 M. S. Park, Y. M. Kang, G. X. Wang, S. X. Dou and H. K. Liu, Adv. Funct. Mater., 2008, 18, 455-461.

157 J. Wang, N. Du, H. Zhang, J. Yu and D. Yang, J. Phys. Chem. $C, 2011,115,11302-11305$.

158 S. H. Kang, J. Kim, M. E. Stoll, D. Abraham, Y. K. Sun and K. Amine, J. Power Sources, 2002, 112, 41-48.

159 Y. M. Kang, M. S. Song, J. H. Kim, H. S. Kim, M. S. Park, J. Y. Lee, H. K. Liu and S. X. Dou, Electrochim. Acta, 2005, 50, 3667-3673.

160 G. X. Wang, Y. Chen, K. Konstantinov, M. Lindsay, H. K. Liu and S. X. Dou, J. Power Sources, 2002, 109, 142-147.

161 Z. Wang, L. Zhou and X. W. Lou, Adv. Mater., 2012, 24, 1903-1911.

162 K. Kang, Y. S. Meng, J. Bréger, C. P. Grey and G. Ceder, Science, 2006, 311, 977-980.

163 N. Yabuuchi, K. Yoshii, S. T. Myung, I. Nakai and S. Komaba, J. Am. Chem. Soc., 2011, 133, 4404-4419.

164 S. Bijani, M. Gabás, L. Martínez, J. R. Ramos-Barrado, J. Morales and L. Sánchez, Thin Solid Films, 2007, 515, 5505-5511.

165 X. P. Gao, J. L. Bao, G. L. Pan, H. Y. Zhu, P. X. Huang, F. Wu and D. Y. Song, J. Phys. Chem. B, 2004, 108, 5547-5551.

166 D. K. Kim, P. Muralidharan, H. W. Lee, R. Ruffo, Y. Yang, C. K. Chan, H. Peng, R. A. Huggins and Y. Cui, Nano Lett., 2008, 8, 3948-3952.

167 M. M. Thackeray, C. S. Johnson, J. T. Vaughey, N. Li and S. A. Hackney, J. Mater. Chem., 2005, 15, 2257-2267.

168 E. Kang, Y. S. Jung, A. S. Cavanagh, G. H. Kim, S. M. George, A. C. Dillon, J. K. Kim and J. Lee, Adv. Funct. Mater., 2011, 21, 2430-2438.

169 B. Koo, H. Xiong, M. D. Slater, V. B. Prakapenka, M. Balasubramanian, P. Podsiadlo, C. S. Johnson, T. Rajh and E. V. Shevchenko, Nano Lett., 2012, 12, 2429-2435.

170 N. Meethong, Y. H. Kao, S. A. Speakman and Y. M. Chiang, Adv. Funct. Mater., 2009, 19, 1060-1070.

171 M. V. Reddy, T. Yu, C. H. Sow, Z. X. Shen, C. T. Lim, G. V. S. Rao and B. V. R. Chowdari, Adv. Funct. Mater., 2007, 17, 2792-2799.
172 B. Wang, J. S. Chen, H. B. Wu, Z. Wang and X. W. Lou, J. Am. Chem. Soc., 2011, 133, 17146-17148.

173 B. Guo, X. Fang, B. Li, Y. Shi, C. Ouyang, Y. S. Hu, Z. Wang, G. D. Stucky and L. Chen, Chem. Mater., 2012, 24, 457-463.

174 M. F. Hassan, Z. P. Guo, Z. Chen and H. K. Liu, J. Power Sources, 2010, 195, 2372-2376.

175 M. Martos, J. Morales and L. Sánchez, J. Mater. Chem., 2002, 12, 2979-2984.

176 T. Tao, A. M. Glushenkov, C. Zhang, H. Zhang, D. Zhou, Z. Guo, H. K. Liu, Q. Chen, H. Hu and Y. Chen, J. Mater. Chem., 2011, 21, 9350-9355.

177 X. Y. Xue, Z. H. Chen, L. L. Xing, S. Yuan and Y. J. Chen, Chem. Commun., 2011, 47, 5205-5207.

178 H. Wang, L. F. Cui, Y. Yang, H. Sanchez Casalongue, J. T. Robinson, Y. Liang, Y. Cui and H. Dai, J. Am. Chem. Soc., 2010, 132, 13978-13980.

179 S. K. Behera, Chem. Commun., 2011, 47, 10371-10373.

180 X. Zhu, Y. Zhu, S. Murali, M. D. Stoller and R. S. Ruoff, ACS Nano, 2011, 5, 3333-3338.

181 S.-L. Chou, J.-Z. Wang, M. Choucair, H.-K. Liu, J. A. Stride and S.-X. Dou, Electrochem. Commun., 2010, 12, 303-306.

182 S.-M. Paek, E. Yoo and I. Honma, Nano Lett., 2008, 9, 72-75.

183 L. Q. Lu and Y. Wang, J. Mater. Chem., 2011, 21, 1791617921.

184 Y. Zou and Y. Wang, Nanoscale, 2011, 3, 2615-2620.

185 S. Chen, P. Chen, M. Wu, D. Pan and Y. Wang, Electrochem. Commun., 2010, 12, 1302-1306.

186 K. Chang and W. Chen, ACS Nano, 2011, 5, 4720-4728.

187 Z. Liu, J. T. Robinson, S. M. Tabakman, K. Yang and H. Dai, Mater. Today, 2011, 14, 316-323.

188 G. A. A. Saracino, D. Cigognini, D. Silva, A. Caprini and F. Gelain, Chem. Soc. Rev., 2013, 42, 225-262.

189 S. Goenka, V. Sant and S. Sant, J. Controlled Release, 2014, 173, 75-88.

190 P. K. Jain, X. Huang, I. H. El-Sayed and M. A. El-Sayed, Acc. Chem. Res., 2008, 41, 1578-1586.

191 S. Yu and C. M. Chow, J. Mater. Chem., 2004, 14, 2781-2786. 192 M. Mahmoudi, A. Simchi, M. Imani, M. A. Shokrgozar, A. S. Milani, U. O. Häfeli and P. Stroeve, Colloids Surf., B, 2010, 75, 300-309.

193 B. Ankamwar, T. C. Lai, J. H. Huang, R. S. Liu, M. Hsiao, C. H. Chen and Y. K. Hwu, Nanotechnology, 2010, 21, 075102.

194 E. S. Guang Choo, X. Tang, Y. Sheng, B. Shuter and J. Xue, J. Mater. Chem., 2011, 21, 2310-2319.

195 D. Dosev, M. Nichkova and I. M. Kennedy, J. Nanosci. Nanotechnol., 2008, 8, 1052-1067.

196 A. Jana, B. Saha, D. R. Banerjee, S. K. Ghosh, K. T. Nguyen, X. Ma, Q. Qu, Y. Zhao and N. D. P. Singh, Bioconjugate Chem., 2013, 24, 1828-1839.

197 H. Zhang, X. Ma, K. T. Nguyen and Y. Zhao, ACS Nano, 2013, 7, 7853-7863.

198 H. Zhang, X. Ma, J. Guo, K. T. Nguyen, Q. Zhang, X.-J. Wang, H. Yan, L. Zhu and Y. Zhao, RSC Adv., 2013, 3, 368-371.

199 Y. Klichko, M. Liong, E. Choi, S. Angelos, A. E. Nel, J. F. Stoddart, F. Tamanoi and J. I. Zink, J. Am. Ceram. Soc., 2009, 92, S2-S10. 
200 I. I. Slowing, B. G. Trewyn, S. Giri and V. S. Y. Lin, Adv. Funct. Mater., 2007, 17, 1225-1236.

201 F. Torney, B. G. Trewyn, V. S. Y. Lin and K. Wang, Nat. Nanotechnol., 2007, 2, 295-300.

202 I. I. Slowing, J. L. Vivero-Escoto, C. W. Wu and V. S. Y. Lin, Adv. Drug Delivery Rev., 2008, 60, 1278-1288.

203 J. Lu, M. Liong, J. I. Zink and F. Tamanoi, Small, 2007, 3, 1341-1346.

204 Z. Luo, X. Ding, Y. Hu, S. Wu, Y. Xiang, Y. Zeng, B. Zhang, H. Yan, H. Zhang, L. Zhu, J. Liu, J. Li, K. Cai and Y. Zhao, ACS Nano, 2013, 7, 10271-10284.

205 Q. Zhang, F. Liu, K. T. Nguyen, X. Ma, X. Wang, B. Xing and Y. Zhao, Adv. Funct. Mater., 2012, 22, 5144-5156.

206 X. Ma, K. T. Nguyen, P. Borah, C. Y. Ang and Y. Zhao, Adv. Healthcare Mater., 2012, 1, 690-697.

207 H. Yan, C. Teh, S. Sreejith, L. Zhu, A. Kwok, W. Fang, X. Ma, K. T. Nguyen, V. Korzh and Y. Zhao, Angew. Chem., Int. Ed., 2012, 51, 8373-8377.

208 C. Wang, Z. Li, D. Cao, Y.-L. Zhao, J. W. Gaines, O. A. Bozdemir, M. W. Ambrogio, M. Frasconi, Y. Y. Botros, J. I. Zink and J. F. Stoddart, Angew. Chem., Int. Ed., 2012, 51, 5460-5465.

209 M. W. Ambrogio, C. R. Thomas, Y.-L. Zhao, J. I. Zink and J. F. Stoddart, Acc. Chem. Res., 2011, 44, 903-913.

210 L. Tang, Y. Wang, Y. Li, H. Feng, J. Lu and J. Li, Adv. Funct. Mater., 2009, 19, 2782-2789.

211 M. Zhou, Y. Zhai and S. Dong, Anal. Chem., 2009, 81, 56035613.

212 X. Luo, A. Morrin, A. J. Killard and M. R. Smyth, Electroanalysis, 2006, 18, 319-326.

213 A. Gutés, C. Carraro and R. Maboudian, Biosens. Bioelectron., 2012, 33, 56-59.

214 O. Parlak, A. Tiwari and A. P. F. Turner, Biosens. Bioelectron., 2013, 49, 53-62.

215 J. Li, D. Kuang, Y. Feng, F. Zhang, Z. Xu, M. Liu and D. Wang, Biosens. Bioelectron., 2013, 42, 198-206.

216 X. Chen, Z. Cai, Z. Huang, M. Oyama, Y. Jiang and X. Chan, Nanoscale, 2013, 5, 5779-5783.

217 C. L. Sun, H. H. Lee, J. M. Yang and C. C. Wu, Biosens. Bioelectron., 2011, 26, 3450-3455.

218 L. M. Lu, H. B. Li, F. Qu, X. B. Zhang, G. L. Shen and R. Q. Yu, Biosens.Bioelectron., 2011, 26, 3500-3504.

219 Q. Wei, Z. Xiang, J. He, G. Wang, H. Li, Z. Qian and M. Yang, Biosens. Bioelectron., 2010, 26, 627-631.

220 Y. Zhuo, Y. Q. Chai, R. Yuan, L. Mao, Y. L. Yuan and J. Han, Biosens. Bioelectron., 2011, 26, 3838-3844.

221 H. Wang, Y. Zhang, H. Li, B. Du, H. Ma, D. Wu and Q. Wei, Biosens. Bioelectron., 2013, 49, 14-19.

222 M. Liu, Q. Chen, C. Lai, Y. Zhang, J. Deng, H. Li and S. Yao, Biosens. Bioelectron., 2013, 48, 75-81.

223 Y. Yu, Z. Chen, S. He, B. Zhang, X. Li and M. Yao, Biosens. Bioelectron., 2014, 52, 147-152.

224 C. Shan, H. Yang, D. Han, Q. Zhang, A. Ivaska and L. Niu, Biosens. Bioelectron., 2010, 25, 1070-1074.

225 W. Lu, Y. Luo, G. Chang and X. Sun, Biosens. Bioelectron., 2011, 26, 4791-4797.
226 Q. Zeng, J. S. Cheng, X. F. Liu, H. T. Bai and J. H. Jiang, Biosens. Bioelectron., 2011, 26, 3456-3463.

227 W. Song, D. W. Li, Y. T. Li, Y. Li and Y. T. Long, Biosens. Bioelectron., 2011, 26, 3181-3186.

228 H. Li, Q. Wei, J. He, T. Li, Y. Zhao, Y. Cai, B. Du, Z. Qian and M. Yang, Biosens. Bioelectron., 2011, 26, 3590-3595.

229 Y. Xue, H. Zhao, Z. Wu, X. Li, Y. He and Z. Yuan, Biosens. Bioelectron., 2011, 29, 102-108.

230 Y. Wang, R. Yuan, Y. Chai, Y. Yuan, L. Bai and Y. Liao, Biosens. Bioelectron., 2011, 30, 61-66.

231 W. Lian, S. Liu, J. Yu, X. Xing, J. Li, M. Cui and J. Huang, Biosens. Bioelectron., 2012, 38, 163-169.

232 F. Xiao, Y. Li, H. Gao, S. Ge and H. Duan, Biosens. Bioelectron., 2013, 41, 417-423.

233 M. Liu, R. Liu and W. Chen, Biosens. Bioelectron., 2013, 45, 206-212.

234 J. Zhang, Y. Sun, B. Xu, H. Zhang, Y. Gao and D. Song, Biosens. Bioelectron., 2013, 45, 230-236.

235 M. Liu, J. Deng, Q. Chen, Y. Huang, L. Wang, Y. Zhao, Y. Zhang, H. Li and S. Yao, Biosens. Bioelectron., 2013, 41, 275-281.

236 J. Yang, J. H. Yu, J. Rudi Strickler, W. J. Chang and S. Gunasekaran, Biosens. Bioelectron., 2013, 47, 530-538.

237 Y. Hu, Z. Xue, H. He, R. Ai, X. Liu and X. Lu, Biosens. Bioelectron., 2013, 47, 45-49.

238 S. Yu, Q. Wei, B. Du, D. Wu, H. Li, L. Yan, H. Ma and Y. Zhang, Biosens. Bioelectron., 2013, 48, 224-229.

239 S. Cao, L. Zhang, Y. Chai and R. Yuan, Biosens. Bioelectron., 2013, 42, 532-538.

240 Y. Sheng, X. Tang, E. Peng and J. Xue, J. Mater. Chem. B, 2013, 1, 512-521.

241 X. Huang, I. H. El-Sayed, W. Qian and M. A. El-Sayed, J. Am. Chem. Soc., 2006, 128, 2115-2120.

242 X. Wu, T. Ming, X. Wang, P. Wang, J. Wang and J. Chen, ACS Nano, 2009, 4, 113-120.

243 H. Park, J. Yang, J. Lee, S. Haam, I.-H. Choi and K.-H. Yoo, ACS Nano, 2009, 3, 2919-2926.

244 F. Zhou, S. Wu, B. Wu, W. R. Chen and D. Xing, Small, 2011, 7, 2727-2735.

245 V. Biju, T. Itoh and M. Ishikawa, Chem. Soc. Rev., 2010, 39, 3031-3056.

246 H. Guo, H. Qian, N. M. Idris and Y. Zhang, Nanomedicine, 2010, 6, 486-495.

247 H. S. Qian, H. C. Guo, P. C. L. Ho, R. Mahendran and Y. Zhang, Small, 2009, 5, 2285-2290.

248 A. F. Zedan, S. Moussa, J. Terner, G. Atkinson and M. S. ElShall, ACS Nano, 2013, 7, 627-636.

249 Y. Wang, H. Wang, D. Liu, S. Song, X. Wang and H. Zhang, Biomaterials, 2013, 34, 7715-7724.

250 X. Shi, H. Gong, Y. Li, C. Wang, L. Cheng and Z. Liu, Biomaterials, 2013, 34, 4786-4793.

251 H. Jaganathan, D. L. Hugar and A. Ivanisevic, ACS Appl. Mater. Interfaces, 2011, 3, 1282-1288.

252 G. Liu, Z. Wang, J. Lu, C. Xia, F. Gao, Q. Gong, B. Song, X. Zhao, X. Shuai, X. Chen, H. Ai and Z. Gu, Biomaterials, 2011, 32, 528-537. 
253 H. Ai, C. Flask, B. Weinberg, X. T. Shuai, M. D. Pagel, D. Farrell, J. Duerk and J. Gao, Adv. Mater., 2005, 17, 1949-1952.

254 J. Lu, S. Ma, J. Sun, C. Xia, C. Liu, Z. Wang, X. Zhao, F. Gao, Q. Gong, B. Song, X. Shuai, H. Ai and Z. Gu, Biomaterials, 2009, 30, 2919-2928.

255 W. Chen, P. Yi, Y. Zhang, L. Zhang, Z. Deng and Z. Zhang, ACS Appl. Mater. Interfaces, 2011, 3, 4085-4091.
256 E. Peng, E. S. G. Choo, P. Chandrasekharan, C. T. Yang, J. Ding, K. H. Chuang and J. M. Xue, Small, 2012, 8, 36203630.

257 M.-L. Chen, L.-M. Shen, S. Chen, H. Wang, X.-W. Chen and J.-H. Wang, J. Mater. Chem. B, 2013, 1, 2582-2589.

258 C. Wang, S. Ravi, U. S. Garapati, M. Das, M. Howell, J. Mallela, S. Alwarappan, S. S. Mohapatra and S. Mohapatra, J. Mater. Chem. B, 2013, 1, 4396-4405.

259 K. Yang, L. Feng, H. Hong, W. Cai and Z. Liu, Nat. Protoc., 2013, 8, 2392-2403. 